\section{Status and Prospects of Organic Redox Flow Batteries toward Sustainable Energy Storage}

\author{
Jian Luo, ${ }^{\dagger}$ Bo Hu, ${ }^{\dagger}$ Maowei $\mathrm{Hu},{ }^{\dagger} \mathrm{Yu}$ Zhao, ${ }^{\dagger}$ and T. Leo Liu ${ }^{*}{ }^{\dagger} \odot$ \\ ${ }^{\dagger}$ The Department of Chemistry and Biochemistry, Utah State University, Logan, Utah 84322, United States \\ ${ }^{\ddagger}$ Key Laboratory of Marine Chemistry Theory and Technology, Ministry of Education, College of Chemistry and Chemical \\ Engineering, Ocean University of China, Qingdao 266100, China
}

\begin{abstract}
Redox flow batteries (RFBs) are regarded a promising technology for large-scale electricity energy storage to realize efficient utilization of intermittent renewable energy. Redox -active materials are the most important components in the RFB system because their physicochemical and electrochemical properties directly determine their battery performance and energy storage cost. Designable, tunable, and potentially low-cost redoxactive organic compounds are promising alternatives to traditional redox-active inorganic compounds for RFB applications. Herein, the representative designs of redox-active molecules, recent development of organic RFBs (ORFBs), and advantages/ disadvantages of different ORFB are reviewed. Especially the relationship between redox-active molecules' physicochemical

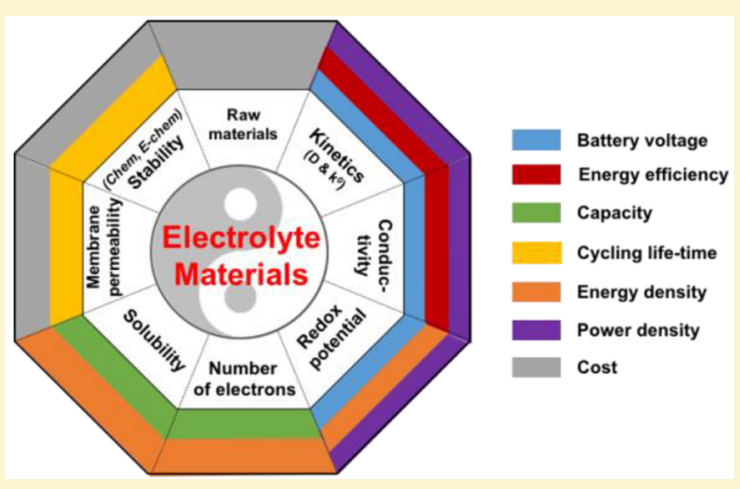
properties and their battery performance is discussed with an emphasis on the side reactions that cause fading of battery capacity. Finally, we provide an outlook on the development of high-performance ORFBs for practical energy storage applications.
\end{abstract}

$\mathrm{W}$ orldwide economic growth drives increasing energy demand, while environmental challenges necessitate the reduction of carbon emissions. ${ }^{1-3}$ Naturally, the development of renewable energy sources, such as solar and wind, has been more rapidly escalated in recent years than ever before. $^{1-3}$ The growth of electricity production from solar and wind is around an average rate of $6.3 \%$ per year. ${ }^{4}$ Meanwhile, between 2008 and 2015, the cost of wind power generation decreased by $41 \%$, the cost of rooftop solar photovoltaic (PV) cells was reduced by $54 \%$, and the cost for utility-scale PVs fell by $64 \%{ }^{5}$ The scale of typical PVs is between $1 \mathrm{~kW}$ (small-scale rooftop system) and 550 MW (Topaz Solar Farm, California, USA), and that of typical wind turbines is between 2.5 and 7.5 MW. Clearly, the momentum toward renewable energy is unalterable. However, it is estimated that $>20 \%$ intermittent renewable energy integration could endanger the stability of the grid. $^{2}$ With the increasing contribution of fluctuating renewable energy sources and distributed power generation to electrical grids, advanced electricity energy storage technologies are urgently needed to overcome the temporal deviation in energy production and consumption. Several energy storage devices, such as secondary batteries (e.g., lead-acid, Li-ion, and flow batteries), flywheels, and electrochemical supercapacitors are available for electricity storage. ${ }^{1-3}$ Because of the technological merits of high power input and output, decoupled energy and power, scalability, and safety features, redox flow batteries (RFBs) are well suited for integration of renewable energy and balancing the storage capacity of electricity grids up to $\mathrm{MW} / \mathrm{MWh}$ ranging from minutes to days. ${ }^{2,3}$

The concept of RFBs was first introduced by the National Aeronautics and Space Administration (NASA) in the 1970s employing $\mathrm{Fe}^{3+/ 2+}$ and $\mathrm{Cr}^{3+/ 2+}$ as redox-active couples in the cathode and anode sides, respectively. ${ }^{6}$ Traditional RFBs utilize inorganic compounds such as $\mathrm{FeCl}_{2}, \mathrm{Zn}$ halides, and $\mathrm{VOSO}_{4}$ as redox-active materials. ${ }^{7}$ Among numerous systems, vanadium RFBs (VRFBs) represent state-of-the-art RFBs and have received a great deal of commercialization efforts. $3,7,8$ However, VRFBs are subjected to a number of technological and economic challenges for widespread applications in electrochemical energy storage (EES), including expensive components (ca. $\$ 24 / \mathrm{kg}$ for $\mathrm{V}_{2} \mathrm{O}_{5}$ raw material and $\$ 500 / \mathrm{m}^{2}$ for Nafion membranes), redox material crossover, side reactions (hydrogen evolution in strong acidic conditions), and corrosive electrolytes. ${ }^{7}$ The state-of-the-art VRFBs (VRFB-Gen2) have an estimated system cost of $\$ 447 / \mathrm{kWh},{ }^{9}$ which is significantly higher than the cost target for energy storage set by the U.S. Department of Energy (DOE), \$100/ $\mathrm{kWh}{ }^{10,11}$ To address the challenges encountered by the existing inorganic RFBs, organic RFBs (ORFBs) employing

Received: June 22, 2019

Accepted: August 12, 2019

Published: August 12, 2019 

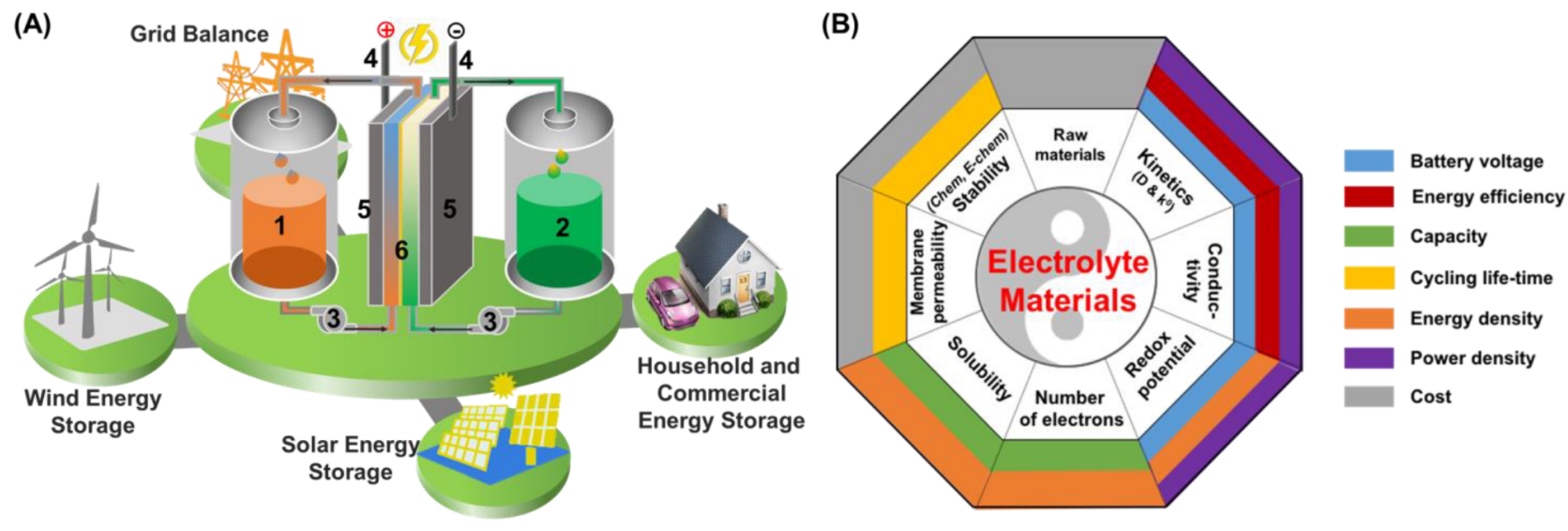

Figure 1. (A) Graphic representation of diverse applications and cell components of RFBs. 1. Catholyte reservoir; 2 . anolyte reservoir; 3. pumps; 4. current collectors; 5. carbon electrodes; 6. separator. (B) Correlation diagram of physicochemical properties of electrolyte materials and performance metrics of RFBs.

sustainable and potentially inexpensive redox-active organic molecules were proposed as the next generation of RFBs for green energy storage. ${ }^{12-14}$ In addition to the general features of traditional inorganic RFBs mentioned above, the ORFBs have several outstanding advantages for large-scale EES: (1) redox molecules consisting of earth-abundant elements are sustainable and can be low-cost in large-scale production; (2) they are synthetically tunable to gain foreseeable and desirable battery performance; and (3) they can be systematically studied using a suite of solution spectroscopies and computational simulations. In the past decade, significant progress has been made in the development of ORFBs, including versatile designs of redox organic molecules and their electrolyte materials, comprehensive electrochemical and physicalorganic studies, and computational modeling studies. Several excellent reviews have summarized material choices and battery performance of the organic RFBs. ${ }^{12-15}$ In this Review, we focus on electrochemistry and physical-organic chemistry of redox-active organic molecules in ORFBs, especially side reactions causing irreversible battery capacity fading. We aim to establish the relationship between the physicochemical properties of redox-active organic and organometallic molecules and their battery performance, which can provide guidance to design more persistent ones for improved battery performance.

Principle of RFBs and Physicochemical Properties of Redox-Active Molecules and Electrolytes. Working Principle of RFBs. A typical battery configuration of RFBs is schematically shown in Figure 1A. A flow battery consists of three major components, two separated electrolyte reservoirs (parts 1 and 2 ), two peristaltic pumps (part 3), and an electrochemical cell (parts 4-6). The electrochemical cell is constructed of two electrolyte chambers that are isolated by a piece of ion -conductive separator (part 6). Electrodes (porous carbon felt or carbon paper, part 5) are connected to the current collectors (part 4) and are submerged in redox-active electrolytes. Redoxactive molecules dissolved in liquid supporting electrolytes are stored in the reservoirs in which redox-active electrolyte used on the anode and cathode sides are called the "anolyte" and "catholyte", respectively. The anolyte and catholyte flow through the electrochemical cell simultaneously by the pumps to proceed with electrochemical reactions. In the charge process, energy is stored by the reduction of the anolyte and oxidation of the catholyte; in the discharge process, the stored energy is outputted by the reoxidation of the anolyte and rereduction of the catholyte. During the charge/discharge process, anions or cations of the supporting electrolyte or counterions of redox-active species act as charge carriers to cross through the separator to balance the charge of the anolyte and catholyte. An ideal separator should have a high ion conductivity for the charge carrier but prevent the crossover of redox-active species. As the space for redox materials storage (tanks) and the electrochemical reactions (electrodes) is physically separated, the stored energy and power of the RFB system are decoupled, making it highly modular and flexible to regulate energy and power generation.

Performance Parameters for RFBs. The battery performance of an RFB can be evaluated by several parameters. First, battery voltage is one of the most basic and important parameters for EES devices as it stands for the highest driving force that a battery can supply. The theoretical battery voltage is determined by the redox potentials of the anolyte and catholyte, but the actual open-circuit overpotential is also affected by the inner resistance of a flow battery and the electrochemical kinetics of redox-active materials (see Figure 1B). The theoretical capacity (abbreviated $C_{a p}$ ) of an electrolyte is defined as the amount of charge $(\mathrm{Ah})$ stored in a given volume of electrolyte, as described in eq 1

$$
\text { Capacity }\left(C_{\text {ap }}\right)=n C F / 3600=n C \times 26.8(\mathrm{Ah} / \mathrm{L})
$$

where $n$ is the number of electrons involved in a redox reaction, $C$ is the concentration of a redox-active material, and $F$ is Faraday's constant. Then, the capacity of an electrolyte is determined by the concentration and the number of electrons of the redox-active molecules. Energy density is one of the most important parameters for an EES device. The theoretical energy density (abbreviated as $E_{\mathrm{d}}$ ) of an RFB is calculated using eq 2

$$
\text { Energy Density }\left(E_{\mathrm{d}}\right)=C_{\mathrm{ap}} V / \mu_{\mathrm{v}}(\mathrm{Wh} / \mathrm{L})
$$

where $C_{a p}$ is the smaller capacity of either the anolyte or catholyte as defined in eq $1, V$ is the battery voltage, and $\mu_{\mathrm{v}}$ is the volume factor and defined as $\mu_{\mathrm{v}}=1+C_{\mathrm{ap}} / C_{\mathrm{ap}}{ }^{\prime}$, where $C_{\mathrm{ap}}{ }^{\prime}$ is the larger capacity of either the anolyte or catholyte. Thus, the energy density of an RFB is concomitantly dictated by the capacities and redox potential of the anolyte and catholyte. Another important battery performance parameter of an RFB 


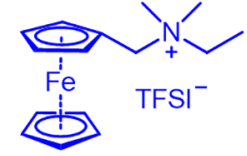

Fc1N112-TFSI, 1

$E_{1 / 2}=0.23 \mathrm{~V}, \mathrm{Vs}$ $\mathrm{FC} / \mathrm{FC}^{+}$

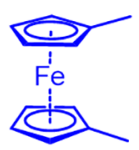

DMFc, 2 $E_{1 / 2}=-0.29 \mathrm{~V}, \mathrm{vs} F \mathrm{~F} / F \mathrm{C}^{+}$

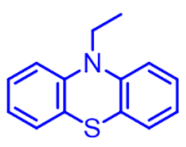

EPT, 3<smiles>COCCOCCN1c2ccccc2Sc2ccccc21</smiles>

MEEPT, 4

$E_{1 / 2}=0.311 \mathrm{~V}, v s F C / F C$ $E_{1 / 2}=0.937 \mathrm{~V}$, vs $F c / F C^{+}$<smiles>CCN1c2ccc(OC)cc2Sc2cc(OC)ccc21</smiles>

DMeOEPT $\mathbf{5}$

$E_{1 / 2}=0.056 \mathrm{~V}$, vs Fc/Fc ${ }^{+}$ $E_{1 / 2}=0.655 \mathrm{~V}$, vs FC/FC ${ }^{+}$<smiles>CCN1c2ccc(OCCOC)cc2Sc2cc(OCCOC)ccc21</smiles><smiles>COCCOc1cc(C(C)(C)C)cc(OC)c1C(C)(C)C</smiles>

ANL-9, 7<smiles>COCCOc1c2c(c(OCCOC)c3c1C1CCC3C1)C1CCC2CC1</smiles>

BODMA, 8<smiles>CCN(CC)c1c(N(CC)CC)[c+]1N(CC)CC</smiles><smiles></smiles>

$E_{1 / 2}=0.064 \mathrm{~V}$, vs FC/FC ${ }^{+}$ $E_{1 / 2}{ }^{\prime}=0.654 \mathrm{~V}$, vs $\mathrm{Fc} / \mathrm{Fc}^{+}$

$E_{1 / 2}=0.33 \mathrm{~V}, \mathrm{vs} \mathrm{FC} / \mathrm{Fc}^{+}$

$E_{1 / 2}=0.58 \mathrm{~V}, \mathrm{vs} F C / F$

$E_{1 / 2}=0.84 \mathrm{~V}$, vs $F c / F c^{+} E_{1 / 2}=-1.14 \sim-1.18 \mathrm{~V}$, vs $F c / F c^{+}$ $E_{1 / 2}=-1.4 \sim-1.8 \mathrm{~V}, \mathrm{vs} F \mathrm{C} / \mathrm{FC}^{+}$

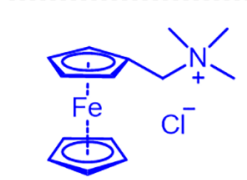

$\mathrm{FCNCl}, 11$ $E_{1 / 2}=0.61 \mathrm{~V}, \mathrm{vs} N H E$<smiles>CN1C(C)(C)CC(O)CC1(C)C</smiles>

4-HO-TEMPO, 12 $E_{1 / 2}=0.8 \mathrm{~V}$. vs NHE<smiles>CN(C)C(C)(C)C1CC(C)(C)NC(C)(C)C1</smiles>

$\mathrm{N}^{\mathrm{Me}}$-TEMPO, 13

$E_{1 / 2}=1.0 \mathrm{~V}, \mathrm{vs} N H E$

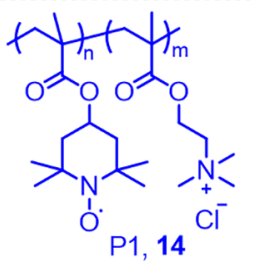

$E_{1 / 2}=0.92 \mathrm{~V}, \mathrm{vs} \mathrm{NHE}$

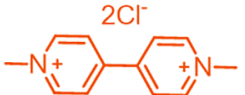

$\mathrm{MVCl}_{2}, 15$ $E_{1 / 2}=-0.45 \mathrm{~V}$, vs NHE

$(\mathrm{SPr})_{2} \mathrm{~V}, 19$ $E_{1 / 2}=-0.43 \mathrm{~V}$, vs NHE

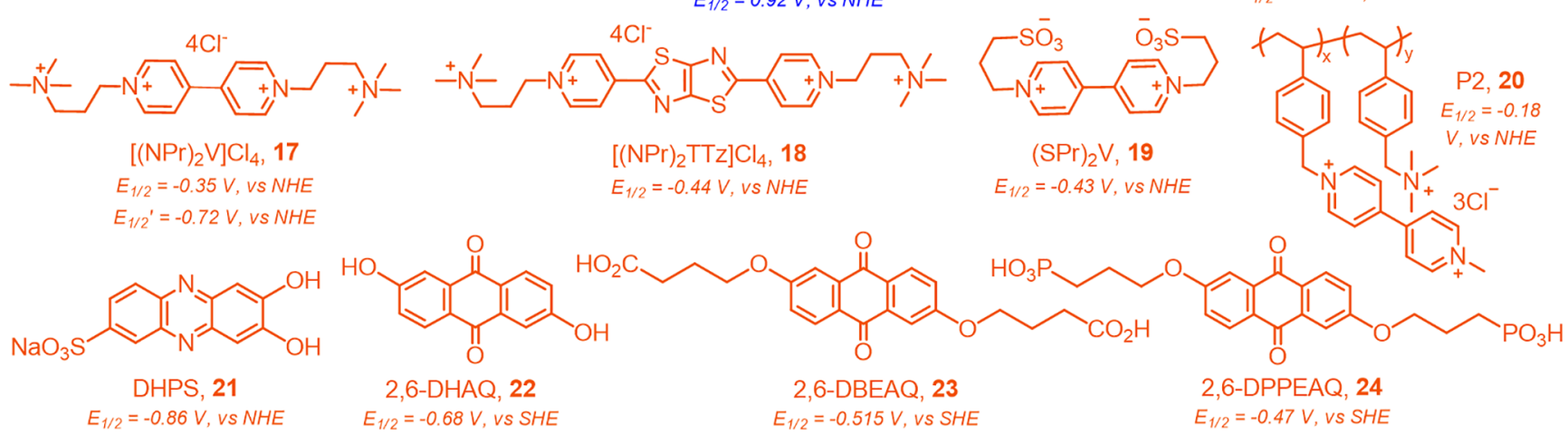

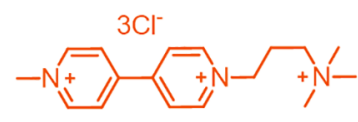

$[(\mathrm{Me})(\mathrm{NPr}) \mathrm{V}] \mathrm{Cl}_{3}, 16$ $E_{1 / 2}=-0.37 \mathrm{~V}$, vs NHE $E_{1 / 2}{ }^{\prime}=-0.74 \mathrm{~V}$, vs NHE

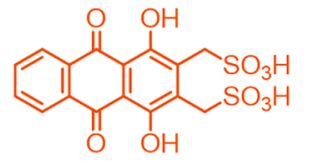

DHAQDMS 28 $E_{1 / 2}=0.02 \mathrm{~V}$, VS SHE<smiles>NS(=O)(=O)c1ccc2c(c1)C(=O)c1cc(S(N)(=O)=O)ccc1C2=O</smiles>

AQDS, 29

$E_{1 / 2}=-0.20 \mathrm{~V}, \mathrm{VS} S H E$

Figure 2. Structures and redox potential of representative electrolyte molecules used in NAORFBs (1- 10) and AORFBs (11-29). Catholyte and anolyte molecules are represented in blue and orange, respectively.

is power density. The power density (abbreviated as $P_{\mathrm{d}}$ ) stands for power per unit area that the battery can supply. It is calculated by eq 3

$$
\text { Power Density }\left(P_{\mathrm{d}}\right)=(I \times V) / S\left(\mathrm{~mW} / \mathrm{cm}^{2}\right)
$$

where $I$ is the discharge current, $V$ is the output potential, and $S$ is the active surface area of an RFB, which is normally determined as the effective area of the separator. The factors that affect the power density are more complicated than those of the capacity and energy density. The power density of an RFB system is mainly affected by the battery voltage, conductivities of the electrolytes, separator, and electrodes, and kinetics of redox reactions. Other operation factors such as temperature, flow rate, and flow field also affect the power density of an RFB.

Capacity utilization, Coulombic efficiency (CE), voltage efficiency (VE), and energy efficiency (EE) are also important parameters for RFBs. Capacity utilization is the ratio of the practical capacity and theoretical capacity of an RFB at a given testing condition. However, reporting capacity utilization and actual capacity has not received enough attention in previous studies in that many studies only reported theoretical capacities. The capacity utilization is mainly affected by battery resistance, operational current densities, and the state of charge (SOC). CE is the ratio of the electrons delivered in the discharge process and the electrons consumed in the charge process, which stands for the reversibility of the battery system. Irreversible side reactions and crossover of redox-active materials can lead to the loss of CE. VE is the ratio of the average discharge voltage and the average charge voltage. $\mathrm{EE}$ is the ratio between the outputted energy in a discharge process and the stored energy in a charge process. VE and EE are mainly affected by battery resistance and operational current densities. The battery resistance for an RFB is the sum of those 
of individual cell components. Usually, a lower battery resistance and smaller charge/discharge current densities would deliver higher capacity utilization, VE, and EE.

Capacity retention of an RFB, which characterizes the cycling lifetime, is traditionally expressed as either a total capacity percentage retained after an extended cycling test or an average retained capacity percentage per cycle. An equivalent expression of capacity retention is a total capacity loss percentage after an extended cycling test or an average capacity loss percentage per cycle. Recently, a number of RFB studies reported capacity retention as an average retained capacity percentage per time. ${ }^{16,17}$ As evident from the literature, ${ }^{16,17}$ capacity retention per cycle does not effectively reflect the chemical stability of redox-active species. For example, fast charge of a small amount of electrolytes can significantly mask their side reactions and favor the value of capacity retention per cycle. As discussed below, these battery performance parameters fully or partly depend on the physical, chemical, and electrochemical properties of the redox-active electrolyte materials.

Physicochemical Properties of Redox-Active Molecules. Redoxactive materials are the most critical components for an RFB as

\section{Redox-active materials are the most critical components for an RFB as the battery performance is mainly deter- mined by the physicochemical proper- ties of electrolyte materials.}

the battery performance is mainly determined by the physicochemical properties of electrolyte materials. In the past decade, a great deal of effort has been made in developing redox-active organic molecules for both aqueous and nonaqueous RFBs applications. In this session, we discuss the important physicochemical properties of redox-active organic and organometallic molecules and their correlation with battery performance, as highlighted in Figure 1B.

Solubility $(C)$. Solubility is the highest concentration of a redox molecule in a solvent or a supporting electrolyte, which is proportional to the theoretical capacity and energy density of an RFB and further affects the installation cost of RFBs. It is necessary and practically meaningful to report the solubility of redox molecules in a supporting electrolyte under both charge and discharge states because usually they have different solubility. However, most of reported studies reported only the solubility of the discharged state, which can be misleading regarding the actual charge capacity of a molecule as it is highly possible that the charged state of a molecule has lower solubility. ${ }^{18}$ Meanwhile, the solubility of electrolytes is highly temperature-dependent; thus, it is necessary to report the solubility together with the measuring temperature. Theoretically, dissolution is a process that overcomes the solute-solute interaction and solvation of a solute molecule. ${ }^{19}$ Thus, high solubility can be obtained by strengthening the solute-solvent interaction or weakening the solute-solute interactions. For example, Wang et al. prepared a highly soluble ionic-derived ferrocene compound, Fc1N112-TFSI (compound 1) ${ }^{20}$ Due to the intensified solvent-ferrocene dynamic interactions through the ionic pendant tetraalkylammonium arm, compound 1 displayed 20-fold higher solubility than the pristine ferrocene. Introducing a poly(ethylene oxide) (PEO) chain is another efficient strategy to improve the solubility of organic compounds. Using this strategy, Odom et al. synthesized highly soluble phenothiazine derivatives, compounds 4 and 6. ${ }^{8,21}$ Compared with the original phenothiazine compound 3, they are miscible with $\mathrm{MeCN}$. The solubility of the charged state of compound 6 is higher than $0.5 \mathrm{M}$ under both radical cation and dication states even in the presence of a supporting electrolyte. Similarly, Zhang et al. prepared a series of catholyte molecules by incorporation of PEO chains with different lengths on one or both sides of the dimethoxy-di-tert-butylbenzene-based redox structure (e.g., compound 7). ${ }^{22}$ The functionality of highly hydrophilic groups, such as ammonium, sulfonate, carboxylate, and phosphate groups, has been employed as an efficient strategy to improve the water solubility of hydrophobic organic/organometallic compounds. The water solubility of ferrocene can be improved to $4.0 \mathrm{M}$ by functionalizing with a pendant tetramethylammonium arm ( $\mathrm{FCNCl}$, compound 11). ${ }^{23}$ It should be noted that counterions can also have a large impact on the solubility of a molecule. $\mathrm{FcNCl}(\mathbf{1 1})$ is highly soluble in water, but its iodide derivative, FcNI, has a solubility less than $100 \mathrm{mM}$ in water. Furthermore, the TFSI derivative of $\mathrm{FcNCl}$ is nearly insoluble in water but highly soluble in $\mathrm{MeCN}{ }^{24}$ Using the $\mathrm{NH}_{4}{ }^{+}$cation to replace $\mathrm{K}^{+}$or $\mathrm{Na}^{+}$as counterions for ferrocyanide $\left(\left[\mathrm{Fe}(\mathrm{CN})_{6}\right]^{4-}\right)$, the solubility of $\left(\mathrm{NH}_{4}\right)_{4}\left[\mathrm{Fe}(\mathrm{CN})_{6}\right]$ is improved to $1.6 \mathrm{M}$, which is more than double that of $\mathrm{K}_{4}\left[\mathrm{Fe}(\mathrm{CN})_{6}\right](0.76 \mathrm{M}$ in water) and $\mathrm{Na}_{4}\left[\mathrm{Fe}(\mathrm{CN})_{6}\right](0.56 \mathrm{M}$ in water $) .^{17}$

Number of Electrons $(n)$. On the basis of eqs 1 and 2, the capacity and energy density of RFBs have liner relationships with the number of electrons involved in redox reactions. Developing multielectron storage molecules is a possible approach to achieve high capacity and energy density of RFBs. Sanford et al. designed a series of two electron storage acylpyridinium-based anolyte molecules by $\mathrm{N}$-alkylation of the single electron redox-active acylpyridine (compound 10, for example). ${ }^{25}$ Methyl viologen $\left(\mathrm{MV}^{2+}\right.$, compound 15) exhibited two single-electron reduction events at -0.45 and $-0.76 \mathrm{~V}$ (vs $\mathrm{NHE}) .^{26}$ However, only the reversible $\mathrm{MV}^{2+/ \bullet+}$ redox event was utilized in aqueous RFBs due to the insolubility of the charge-neutral $\mathrm{MV}^{0}$ state in aqueous solution. ${ }^{26}$ Liu et al. reported the molecular engineering of viologen by functionalization with hydrophilic substituents to obtain $[(\mathrm{Me})(\mathrm{NPr})$ $\mathrm{V}] \mathrm{Cl}_{3}(16)$ and $\left[(\mathrm{NPr})_{2} \mathrm{~V}\right] \mathrm{Cl}_{4}(17)$ for two-electron storage, achieving a lower reduction potential and a higher charge capacity for RFB applications simultaneously. ${ }^{26}$

Redox Potential. The redox potential is one of the most important electrochemical properties for redox-active molecules that determine the battery voltage. It further affects the energy density and power density of an RFB. The combination of a catholyte compound with a higher redox potential and an anolyte compound with a lower redox potential is expected to achieve a higher battery voltage. For organic and organometallic molecules, their redox potential is governed by the energy levels of their frontier HOMO (oxidation) and LUMO (reduction) orbitals, which are highly tunable through structural functionalization. The general trend is that adding electron-donating groups or removing electron-withdrawing groups leads to negative shift of the redox potential. In contrast, adding electron-withdrawing groups or removing electron-donating groups leads to a positive shift of the redox potential. For example, by introducing electron-donating hydroxyl groups and removing or changing the site of the electron-withdrawing sulfonic acid groups, the redox potentials 
(A)

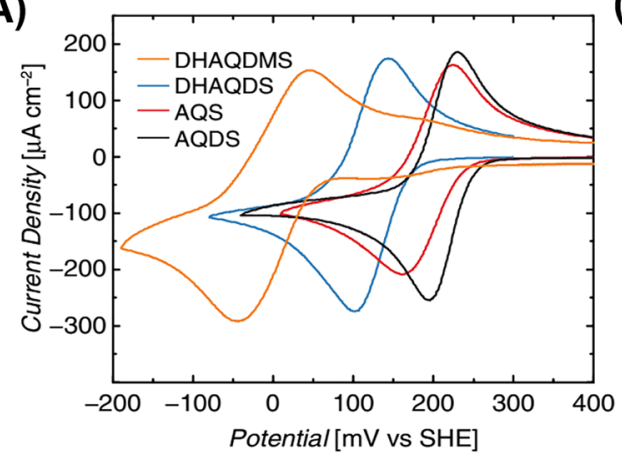

(B)

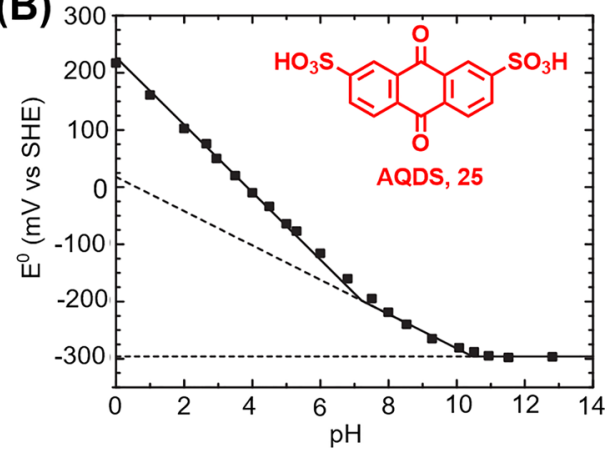

(C)

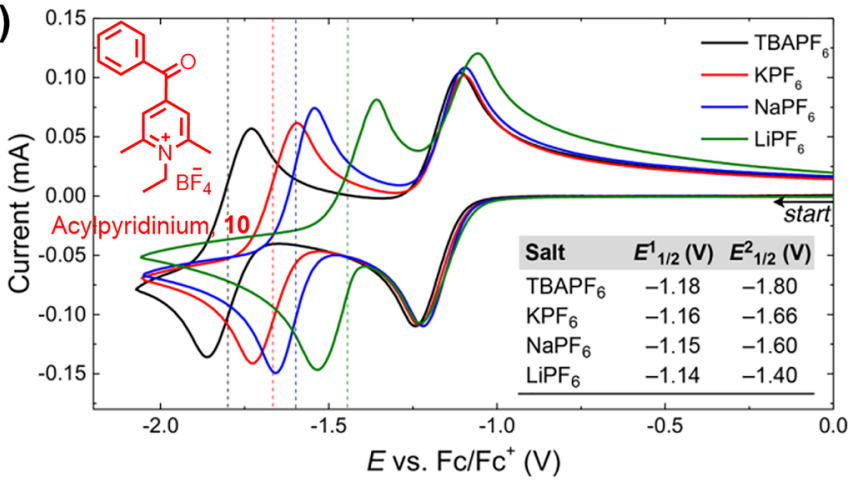

Figure 3. (A) CV curves of compounds $25-28$ (adapted with permission from Wiley). ${ }^{27}$ (B) Pourbaix diagram $\left(E^{0} \mathrm{vs} \mathrm{pH}\right)$ of 25 (adapted with permission from Springer Nature) ${ }^{28}$ (C) CV curves of compound 10 in the presence of different supporting electrolytes (adapted with permission from the American Chemical Society). ${ }^{29}$

of anthraquinone derivatives (compounds 25-28 and Figure $3 \mathrm{~A}$ ) are shifted from +0.21 to $+0.02 \mathrm{~V}$ vs SHE. ${ }^{28}$

The redox potential of the organic molecules can also be affected by the solution environment, such as the $\mathrm{pH}$ value and supporting electrolytes. For example, the redox potential of quinone compounds such as 25 shifted from +0.21 to $-0.3 \mathrm{~V}$ as the $\mathrm{pH}$ increased from 0 to 11 because of proton-coupled electron transfer (PCET) reactions, as mapped out in its Pourbaix diagram (Figure $3 \mathrm{~B}$ ). ${ }^{28}$ In the nonaqueous solution, both redox waves of compound $\mathbf{1 0}$ shifted to less negative when using supporting electrolytes with a stronger Lewis acid cation (Figure 3C). ${ }^{29}$

Stability. The chemical and electrochemical stability of redox-active molecules directly determines the cycling lifetime of RFBs and further affects the cost of EES. ${ }^{30}$ Thus, designing highly stable redox-active compounds is the most challenging but foremost important tasks in developing ORFBs. For practical RFB applications, both discharged and charged states of redox molecules must be stable at high concentrations $(\geq 0.5$ $\mathrm{M})$ in a supporting electrolyte at a certain temperature range (recommended from -30 to $50{ }^{\circ} \mathrm{C}$ ). Physical-organic

\section{Physical-organic chemistry plays an essential role in understanding the degradation mechanism of a redox- active molecule and designing better ones.}

chemistry plays an essential role in understanding the degradation mechanism of a redox-active molecule and designing better ones. Extension of the delocalization of charge in $\mathrm{N}$-ethylphenothiazine (compound 3) with electrondonating methoxy groups can effectively stabilize the DMeOEPT (compound 5) dication. ${ }^{31}$ Incorporating bicyclic substitutions and PEO chains into the dialkoxybenzenes to suppress parasitic radical reactions, Zhang et al. developed a novel catholyte molecule, BODMA (compound 8), which exhibited improved solubility and superior chemical stability in the charged state compared to other derivatives. ${ }^{22}$ Liu et al. applied the " $\pi$-conjugated extension" strategy to stabilize the two-electron reduced viologen compounds. Compared with the viologen compound 17, the "extended viologen" (18) delivered significantly improved stability in a two-electron storage battery cycling process. ${ }^{32}$ Sanford et al. screened a series of acylpyridinium-based anolyte redox molecules. ${ }^{25}$ With the protection of a perpendicular xylyl substituent, homocoupling of two pyridine radicals at $\mathrm{C} 2$ and $\mathrm{C} 5$ positions was suppressed. $^{25}$ Then, compound $\mathbf{1 0}$ was obtained as the most stable molecule in these molecules in a nonaqueous electrolyte.

Electrochemical Kinetics. There are two fundamental parameters to characterize the electrochemical kinetics of redox-active molecules: the diffusion coefficient $(D)$ and electron transfer rate constant $\left(k^{0}\right) .^{33}$ The diffusion coefficient (D) describes the mass transport of a redox-active species from the bulk solution to the electrode surface. The electron transfer rate constant $\left(k^{0}\right)$ defines the charge transfer reaction of a redox-active species at the electrode surface. Diffusion and charge transfer properties of a redox-active molecule are correlated with the mass transport overpotential (or mass transport resistance) and charge transfer overpotential (or charge transfer resistance) observed in a flow battery, respectively. Larger $D$ and $k^{0}$ will result in smaller mass transport and charge transfer overpotential. The literature has shown that organic molecules have a larger $D$ and $k^{0}$ than 
simple inorganic compounds. Electrochemical kinetic studies can provide fundamental information on how the molecular structure of redox-active species, supporting electrolytes, electrode materials, and temperature affect battery performance.

Mass transport in solution is mainly affected by the size and shape of molecules, the supporting electrolyte (viscosity), and the temperature. The Levich equation (eq 4) and Cottrell equation (eq 5) are commonly applied for the measurement of the diffusion coefficient $(D)^{33}$

$$
i=(0.620) n F A C_{0} D^{2 / 3} \omega^{1 / 2} v^{-1 / 6}
$$

where $i$ is the limiting current density from rotation disk electrode (RDE) tests, $A$ is the area of the RDE, $n$ is the number of electrons of a redox reaction, $F$ is $96485 \mathrm{C} / \mathrm{mol}, C_{0}$ is the concentration of an analyte, $D$ is the diffusion coefficient, $\omega$ is the angular rotation rate of an $\mathrm{RDE}$ electrode, and $v$ is the kinematic viscosity.

$$
i=n F A C_{0} D^{1 / 2} /(\pi t)^{1 / 2}
$$

where $n, F, A, C_{0}$, and $D$ are defined in eq $4, i$ is the current, and $t$ is the time (s).

Mass transport can be accelerated by enhancing the flow rate of electrolytes in an RFB, and thus, the mass transport overpotential can be minimized. The electron transfer rate constant $k^{0}$ is affected by the structural nature of redox-active species, electrode materials, supporting electrolyte (including electrolyte salts and solvent), and temperature. For slow kinetic $\left(k^{0}<0.02 \mathrm{~cm} / \mathrm{s}\right)$ where a redox reaction is not electrochemically reversible, $k^{0}$ can be calculated by Koutecký-Levich and Tafel equations (eq 6) based on the linear scan voltammogram (LSV) curves collected by an RDE. $^{33}$

$$
i_{\mathrm{o}}=n F A C_{0} k^{0}
$$

where $n, F, A$, and $C_{0}$ are defined above and $i_{0}$ is the exchange current.

For fast kinetics $\left(k^{0}>0.02 \mathrm{~cm} / \mathrm{s}\right)$, the accurate determination of $k^{0}$ can be more complicated by involving the electrochemical measurement using a microelectrode and digital simulations. More conveniently, fast $k^{0}(>0.02 \mathrm{~cm} / \mathrm{s})$ can be calculated using Nicholson's method based on the $\operatorname{peak}\left(E_{\mathrm{pc}}\right)-\operatorname{peak}\left(E_{\mathrm{pa}}\right)$ separation, $\Delta E_{\mathrm{p}}$, of $\mathrm{CV}$ curves (eqs 7 and 8$).{ }^{34}$ However, for $\Delta E_{\mathrm{p}}<61 \mathrm{mV}$, Nicholson's method can only estimate a lower-bound value using $\Psi=20^{34}$

$$
\begin{aligned}
& \Psi=\left(-0.6288+0.0021 \Delta E_{\mathrm{p}}\right) /\left(1-0.017 \Delta E_{\mathrm{p}}\right) \\
& \Psi=k^{0}[\pi \mathrm{D} n \mathrm{~F} / \mathrm{RT}]^{-1 / 2} v^{-1 / 2}
\end{aligned}
$$

where $F, D$, and $n$ are defined above and $v$ represents the scan rate.

It should be reminded that if one applies Koutecký-Levich and Tafel equations to determine a rate constant for a fast redox reaction then it may significantly underestimate $k^{0}$. For example, $k^{0}$ of the first redox event of methyl viologen (MV, 15) was calculated as $0.022 \mathrm{~cm} / \mathrm{s}$ using the Koutecký-Levich equation; ${ }^{35}$ however, it was determined as $0.35 \mathrm{~cm} / \mathrm{s}$ by Nicholson's method. ${ }^{26}$

Membrane Permeability. The crossover of redox-active species through a membrane can lead to $\mathrm{CE}$ loss and irreversible capacity decay. Thus, besides the chemical and electrochemical stability of redox-active molecules, their membrane permeability is another important factor that determines the cycling lifetime of RFBs. In aqueous flow batteries, ion-exchange membranes that selectively mediate cations or anions of supporting electrolytes are commonly used to avoid the crossover of redox-active species. In terms of molecular design, introducing charged groups into redox-active scaffolds can efficiently improve the selectivity of the membrane and minimize the crossover of redox-active molecules. For example, Schubert et al. developed a positively charged TEMPO compound $\mathrm{N}^{\mathrm{Me}}$-TEMPO, compound 13 , as a cathode molecule. ${ }^{38}$ Compared with the charge-neutral 4-HOTEMPO, compound 12, which can cross over an anion exchange membrane, the corresponding battery stability using $\mathrm{N}^{\mathrm{Me}}$-TEMPO as the catholyte was significantly improved. ${ }^{35}$ Another strategy to avoid the redox molecule's crossover is to increase the molecular size. For example, Schubert et al. synthesized TEMPO-based (14) and viologen-based (20) polymers for aqueous ORFB application. ${ }^{39}$ Using a porous cellulose-based dialysis membrane, the battery delivered good stability without apparent crossover. ${ }^{39}$ Recently, the Helms and Sanford groups developed dimeric, trimeric, and oligomeric redox-active molecules specifically tailored for pairing with size-exclusion membranes composed of polymers of intrinsic microporosity, PIM-1 membrane (Figure 4). ${ }^{36,37}$ Benefiting from the highly effective size exclusion, the redox-active oligomers displayed up to 100000 times slower diffusion than the monomer through the PIM-1 membrane.

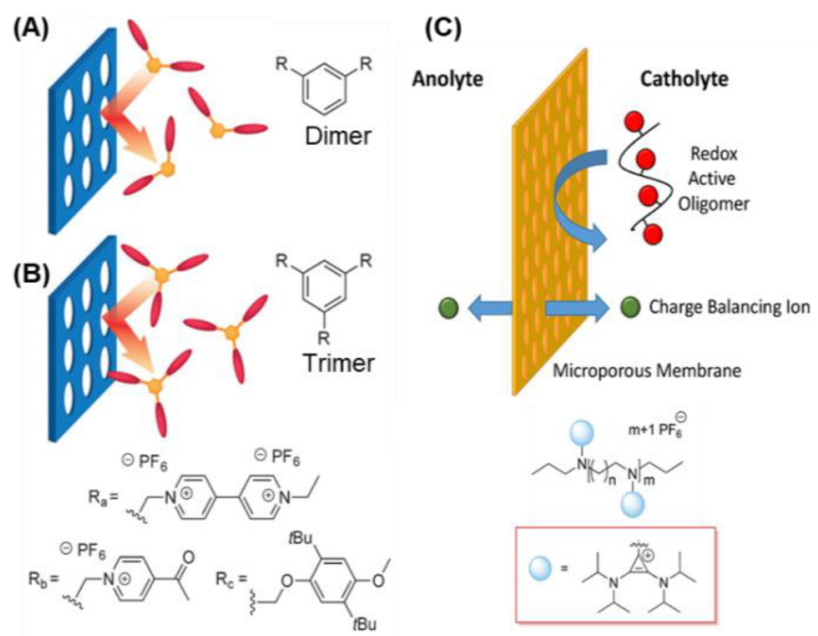

Figure 4. Schematic representation of the operation of a microporous membrane in a flow battery using redox-active oligomers: (A) dimer, (B) trimer, (adapted with permission from Wiley), ${ }^{36}$ and (C) linear oligomers (adapted with permission from the American Chemical Society). ${ }^{37}$

Conductivity. The conductivity of a redox-active electrolyte is an important physical parameter that significantly affects the battery performance including the open-circuit voltage (OCV), $\mathrm{EE}$, capacity utilization, and power density. A low conductivity of a redox-active electrolyte leads to a high inner Ohmic resistance; thus, the output voltage, $\mathrm{EE}$, and power density of RFBs are subject to loss. Charge-neutral organic molecules usually lead to decreasing conductivity of a supporting electrolyte due to the decreased polarity and increased viscosity of solution. In contrast, redox-active molecules functionalized with negatively or positively charged groups 
will have higher conductivities after dissolving into the same supporting electrolyte than charge-neutral molecules. For example, in $2.0 \mathrm{M} \mathrm{NaCl}$, the cationic viologen, $\mathrm{MVCl}_{2}$ (15, $0.5 \mathrm{M}, 159.8 \mathrm{mS} / \mathrm{cm})$, and $(\mathrm{NPr})_{2} \mathrm{VCl}_{4}(17,0.5 \mathrm{M}, 146.8 \mathrm{mS} /$ $\mathrm{cm}){ }^{26}$ possess higher conductivities than charge-neutral $(\mathrm{SPr})_{2} \mathrm{~V}(19,0.5 \mathrm{M}, 101.7 \mathrm{mS} / \mathrm{cm}) .{ }^{40}$ One can use a highconcentration supporting electrolyte to enhance the conductivity of the corresponding redox-active electrolyte. However, it needs to keep in mind that a higher concentration of a supporting electrolyte will decrease the solubility of redoxactive molecules and thus the battery capacity. Depending on the operation priority of the energy density or power density, it is necessary to make a good balance between the conductivity and capacity of a redox-active electrolyte.

Cost. Cost is one of the most important considerations for practical application of an RFB system. ${ }^{41}$ Due to the use of expensive vanadium materials, high cost is the main disadvantage of traditional all-vanadium redox flow batteries (VRFBs). ${ }^{7}$ In contrast, organic redox-active materials contain earth-abundant atoms, such as carbon, nitrogen, sulfur, hydrogen, and oxygen, and can be sustainable and inexpensively manufactured on large scales. In the discovery of redox-active molecules, the price of raw chemicals and solvents, synthesis routes, reaction conditions, and chemical waste treatment need to be comprehensively considered. Moreover, the material cost of individual cell components is also an important aspect to emphasize in the development of practical RFB technologies. There were a few efforts made to estimate the cost of RFBs, but cost estimation has not been extensively applied to reported ORFB chemistries. ${ }^{9,35,42}$

Classification of ORFBs. In the past decades, different types of ORFBs were developed for EES demonstration. On the basis of the solvent used in electrolytes, ORFBs can be divided as aqueous ORFBs (AORFBs), nonaqueous ORFBs (NAORFBs), and hybrid aqueous/nonaqueous RFBs (HORFBs) (Figure 5). AORFBs can be further divided into acidic, neutral, and alkaline AORFBs based on the $\mathrm{pH}$ value of electrolytes. NAORFBs can be divided into all-organic, hybrid

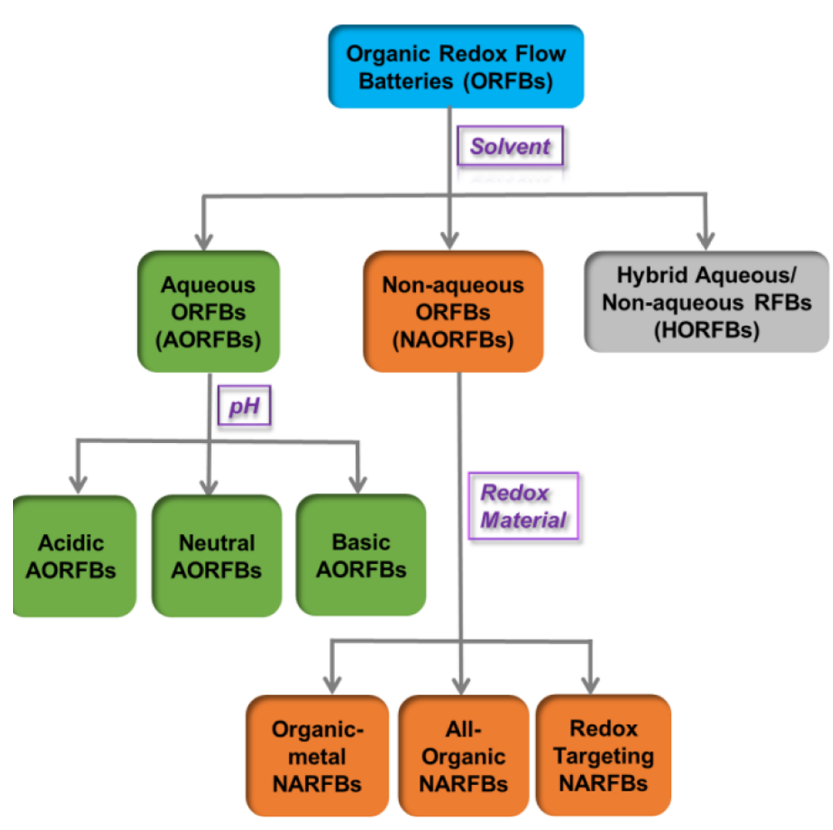

Figure 5. Classification of ORFBs. organic-metal, and redox-targeting flow batteries based on the nature of the redox materials. HORFBs will not be discussed as they need to be further demonstrated for performance viability. ${ }^{43}$ In this section, we discuss the advantages and challenges of each class of ORFBs. Through representative examples, we will discuss how the physicochemical properties of redox-active molecules affect the cycling performance of ORFBs. Particularly, we will emphasize possible degradation mechanisms of redox molecules and further discuss how molecular engineering that is driven by mechanistic understandings improves their chemical and electrochemical stability to boost their battery performance.

Chemistries of AORFBs. In addition to tunability and sustainability, AORFBs reserve technological merits of AIRFBs: (1) utilization of nonflammable aqueous electrolytes offers safety benefits; (2) aqueous electrolytes consisting of water and simple inorganic supporting electrolytes such as $\mathrm{HCl}, \mathrm{NaCl}$, and $\mathrm{KOH}$ are inexpensive; and (3) high conductivity of aqueous electrolytes and well-developed selective ion-conductive membranes for aqueous electrolytes lead to a low area-specific resistance of an RFB, which allows high current and power operation while achieving high energy efficiencies. With these advantages, AORFBs are believed to be

\section{With these advantages, AORFBs are believed to be the most promising systems among different ORFB designs for low-cost, safe, large-scale EES.}

the most promising systems among different ORFB designs for low-cost, safe, large-scale EES. In the past years, significant progress has been made in the emerging AORFB technology, such as high-power acidic ${ }^{28,44}$ and alkaline AORFBs ${ }^{45-49}$ and high-voltage, stable, benign ne utral AORFBs. $^{16,17,23,26,35,38-40,50-52}$

$p H$ Neutral AORFBs. Benefiting from the use of noncorrosive and nonflammable $\mathrm{pH}$-neutral aqueous electrolytes with inexpensive simple inorganic salts (e.g., $\mathrm{NaCl}$ ) as supporting electrolytes, neutral AORFBs offer safety advantages, low cost, and environmentally benign benefits. ${ }^{23,26}$ Additionally, the neutral $\mathrm{pH}$ electrolytes can effectively mitigate undesired side reactions such as hydrogen evolution (occurring at acidic conditions), oxygen evolution (taking place at alkaline conditions), and acid or base involved or catalyzed chemical degradation of redox-active materials, which are typically observed in acidic and alkaline AORFBs. Thus, $\mathrm{pH}$-neutral AORFBs have demonstrated the most stable cycling performance so far. ${ }^{16,17,23,50}$

The first totally organic $\mathrm{pH}$-neutral AORFBs were independently reported by Schubert et al. ${ }^{39}$ and Liu et al. ${ }^{35}$ in 2015. In the work reported by Schubert et al., soluble viologen (20) and TEMPO (14) based polymers were used as the anolyte and catholyte, which has not been further developed most likely due to synthesis challenges. ${ }^{39}$ Liu et al. employed single molecules, specifically, MV (compound 15) and 4-HO-TEMPO (compound 12) as the anolyte and catholyte, respectively, using a $\mathrm{Cl}^{-}$anion exchange mechanism (Figure 6A), ${ }^{35}$ which has led to systemic structural modulation for improved battery performance, as discussed below. It is interesting to note that both viologen/TEMPO AORFBs delivered comparable performance at $0.5 \mathrm{M}$. Compound 15 displayed a solubility up to $3.0 \mathrm{M}$ in water with a redox 


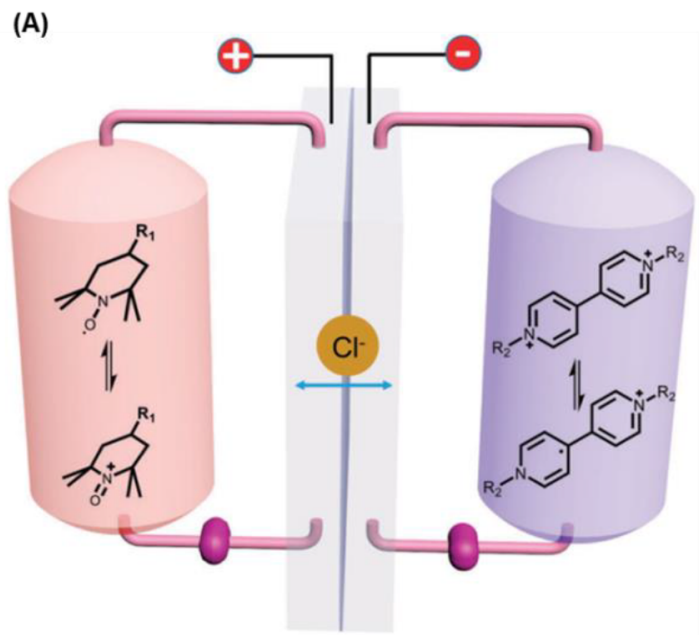

(B)

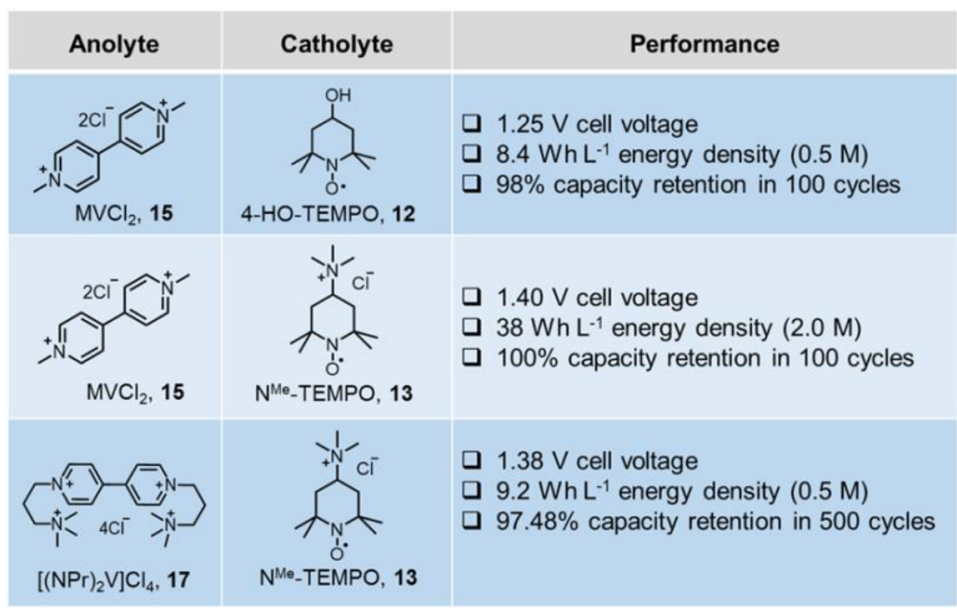

Figure 6. (A) Schematic representation of viologen/TEMPO anion exchange AORFBs and illustrations of discharged and charged states of the viologen anolyte and TEMPO catholyte and cell reactions. (B) Overview of viologen/TEMPO AORFBs reported to date (adapted with permission from the Royal Chemical Society). ${ }^{50}$

potential at $-0.45 \mathrm{~V}$ (vs NHE) for the reversible $\mathrm{MV}^{2+/ \bullet+}$ redox couple. With a hydrophilic $-\mathrm{OH}$ group at the para position, compound 12 exhibited an appreciable solubility, ca. 2.1 $\mathrm{M}$ in water, with a fairly high oxidation potential at $+0.80 \mathrm{~V}$ (vs NHE) assigned to the single-electron redox couple of nitroxyl radical/oxoammonium. The MV/4-HO-TEMPO combination delivered a $1.25 \mathrm{~V}$ cell voltage. Using a Selemion AMV anion-exchange membrane, a 0.1 M MV/4-HO-TEMPO AORFB was operated under high current densities ranging from 20 to $100 \mathrm{~mA} \mathrm{~cm}^{2}$, which delivered $\mathrm{EE}$ up to $83 \%$ (under $20 \mathrm{~mA} / \mathrm{cm}^{2}$ ) with 100 stable charge/discharge cycles and nearly $100 \%$ CE (under $40 \mathrm{~mA} / \mathrm{cm}^{2}$ ). Further increasing the concentration of electrolytes to $0.5 \mathrm{M}$, improved $\mathrm{EE}$ and capacity utilization were observed due to the improved conductivities of electrolytes. However, the cycling stability was significantly decreased mainly due to the crossover of charge-neutral 4-HO-TEMPO. To avoid the crossover of compound 12, Schubert et al. functionalized TEMPO with a cationic trimethylammonium group to obtain a more robust $\mathrm{N}^{\mathrm{Me}}$-TEMPO, $13 .^{38}$ The introduction of a hydrophilic ammonium group not only improved the solubility of the TEMPO compounds, for example, $3.2 \mathrm{M}$ in a $0.3 \mathrm{M} \mathrm{NaCl}$ solution, but also positively shifted the redox potential by 0.15 $\mathrm{V}$ due to the electron-withdrawing effect of the trimethylammonium group. More importantly, the positive charge of compound 13 reduced its permeability compared to 4-HOTEMPO in the anion exchange membrane, which significantly improved the cycling performance of the battery.

TEMPO compounds were reported as efficient catalysts for electrocatalytic alcohol oxidation. ${ }^{53}$ The hydroxyl group of compound $\mathbf{1 2}$ could be oxidized to ketone through a PCET process by the charged state of compound 12 (oxoammonium). Simultaneously, the nitroxyl radical was reduced to non-redox-active hydroxylamine (Figure 7A). The selfcatalyzed alcohol oxidation of the neutral nitroxyl radical compound 12 was a possible side reaction in the MV/4-HOTEMPO AORFB. ${ }^{35}$ The literature also reported the disproportionation of TEMPO radicals to oxoammonium and a nitroxyl anion with an equilibrium constant of $K_{\text {disp }}=$ $10^{-7}$; the latter was further protonated to non-redox-active hydroxylamine with an equilibrium constant of $K_{\text {prot }}=10^{9} \mathrm{M}^{-1}$
(A)

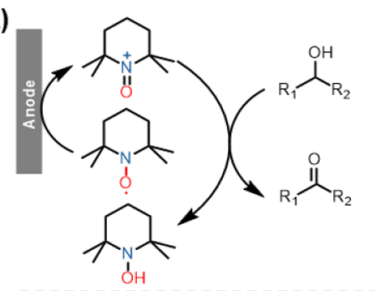

(B)

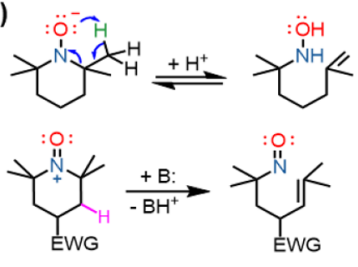

(C)

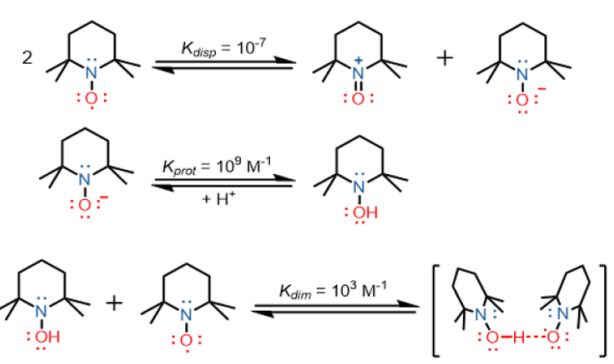

Figure 7. Possible side reaction of the TEMPO compounds: (A) TEMPO-catalyzed alcohol oxidation, (B) ring cleavage degradation of TEMPO compounds, and (C) disproportionationdimerization of TEMPO.

(Figure $7 \mathrm{C}){ }^{54}$ The dimerization between hydroxylamine and the TEMPO free radical with an equilibrium constant of $K_{\mathrm{dim}}=$ $10^{3} \mathrm{M}^{-1}$ could further shift the disproportionation of TEMPO radicals forward. ${ }^{54}$ It is possible that charge-bearing or sterichindering groups will stabilize TEMPO molecules by minimizing the bimolecular interaction. Additionally, the intramolecular proton transfer ring-opening reaction of a nitroxyl anion in an acidic environment and the deprotonation ring-opening reaction of an oxoammonium cation in basic conditions were also reported as possible degradation pathways of TEMPO compounds (Figure 7B). ${ }^{55,56}$ Thus, future designs of TEMPO catholyte molecules should consider how to avoid these side reactions.

To overcome the crossover and low solubility issues of 4 HO-TEMPO, Liu et al. developed ammonium-functionalized highly water-soluble ferrocene molecules as catholytes, e.g., (ferrocenylmethyl)trimethylammonium chloride $(\mathrm{FcNCl}$, compound $\mathbf{1 1}$ in Figure 2) and $\mathrm{N}_{1}$-ferrocenylmethyl- 
(A)

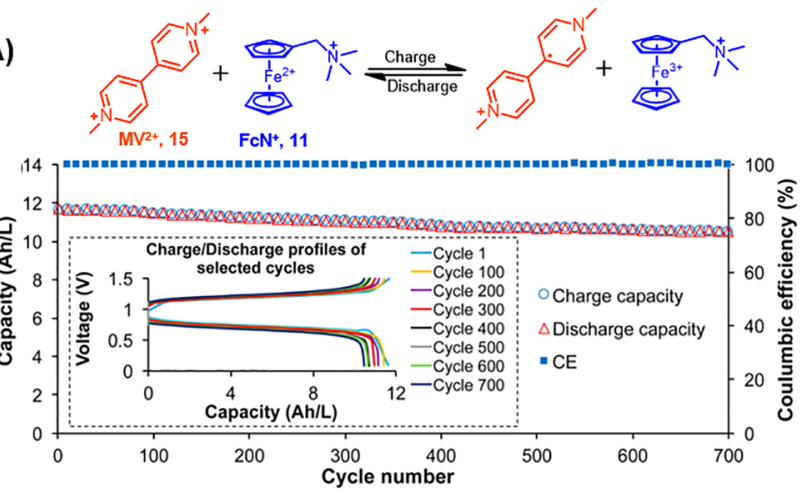

(C)
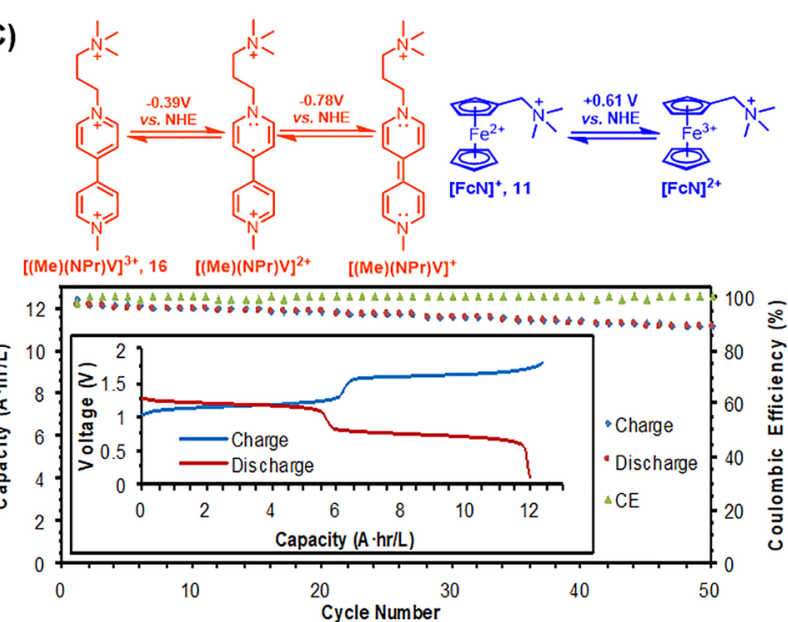

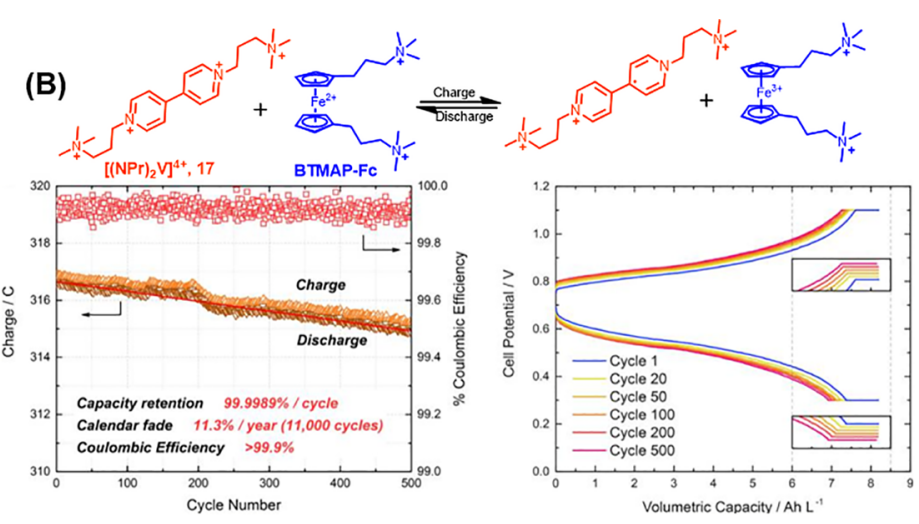

(D)
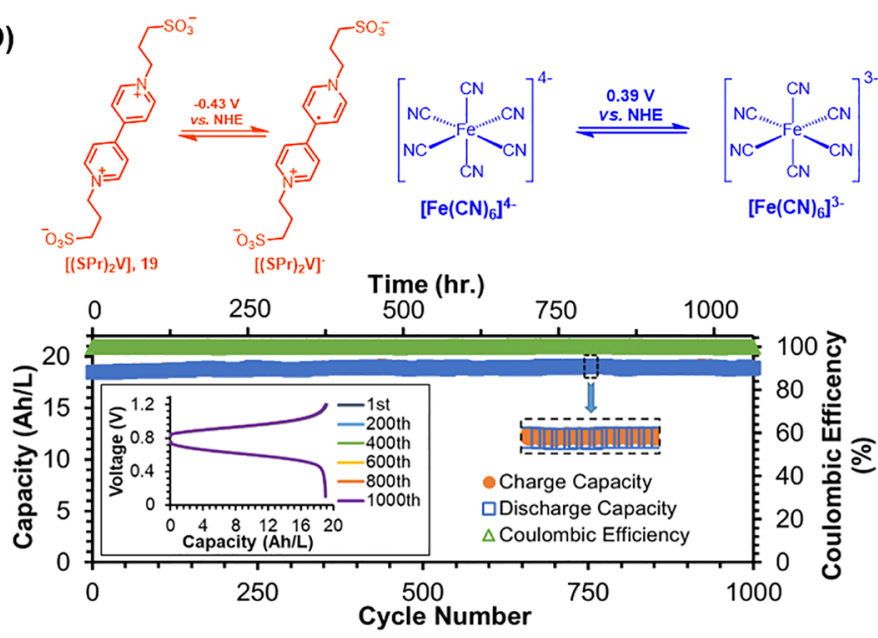

Figure 8. (A) Battery reaction and cycling performance of the AORFB based on compounds 11 (catholyte) and 15 (anolyte) (adapted with permission from the American Chemical Society). ${ }^{23}$ (B) Battery reaction and cycling performance of the AORFB based on compounds BTMAP-Fc (catholyte) and $\left[(\mathrm{NPr})_{2} \mathrm{~V}\right]^{4+}\left(17\right.$, anolyte) (adapted with permission from the American Chemical Society). ${ }^{16}$ (C) Half-cell reactions and cycling performance of the two-electron storage battery based on compounds 11 (catholyte) and 16 (anolyte) (adapted with permission from Elsevier). ${ }^{26}$ (D) Half-cell reactions and cycling performance of highly stable AORFB based on compound 19 (anolyte) and $\left(\mathrm{NH}_{4}\right)_{4}\left[\mathrm{Fe}(\mathrm{CN})_{6}\right]$ (catholyte)

$\mathrm{N}_{1}, \mathrm{~N}_{1}, \mathrm{~N}_{2}, \mathrm{~N}_{2}, \mathrm{~N}_{2}$-pentamethylpropane-1,2-diaminium dibromide, $\left(\mathrm{FcN}_{2} \mathrm{Br}_{2}\right){ }^{23} \mathrm{FcNCl}$ displays extremely high solubility, 4.0 $\mathrm{M}$ in $\mathrm{H}_{2} \mathrm{O}, 107.2 \mathrm{Ah} / \mathrm{L}$, and $3.0 \mathrm{M}$ in $2.0 \mathrm{NaCl}, 80.4 \mathrm{Ah} / \mathrm{L}$, and represents the catholyte molecule with the highest charge capacity. Compared to the pristine ferrocene (insoluble in water, $0.4 \mathrm{~V}$ vs $\mathrm{NHE}$ ), $\mathrm{FcNCl}$ with the hydrophilic and electron-withdrawing ammonium group not only exhibits much higher solubility in aqueous solutions but also possesses a more positive redox potential at $0.61 \mathrm{~V}$ vs NHE. A $0.5 \mathrm{M}$ $\mathrm{MV} / \mathrm{FcNCl}$ AORFB (1.01 V cell voltage) demonstrated excellent cycling performance from 40 to $100 \mathrm{~mA} / \mathrm{cm}^{2}$ with an $\mathrm{EE}$ of up to $72 \%$ at $40 \mathrm{~mA} / \mathrm{cm}^{2}$. The battery exhibited an impressive cycling stability for 700 cycles at $60 \mathrm{~mA} / \mathrm{cm}^{2}$ with a total capacity retention of $90 \%$ or $99.99 \%$ per cycle (Figure $8 \mathrm{~A})$.

There are two possible degradation routes for ferrocenium molecules even though ferrocene molecules are known to be chemically robust. Favratto et al. reported the oxygen decomposition of ferrocenium $\left(\mathrm{Fc}^{+}\right)$in $1998 .{ }^{57}$ As shown in Figure 9A, in the first step, two ferroceniums react with an oxygen molecule to generate an unstable dimeric complex with an -O-O- bridge. Then, this dimer complex further reacts with oxygen and water and decomposes to form an $\mathrm{Fe}^{3+}$ ion, $\mathrm{Fe}^{3+}$ oxide, cyclopendiene, and $\mathrm{Cp}$ peroxide. Thus, it is important to exclude $\mathrm{O}_{2}$ from battery tests. The decomposition

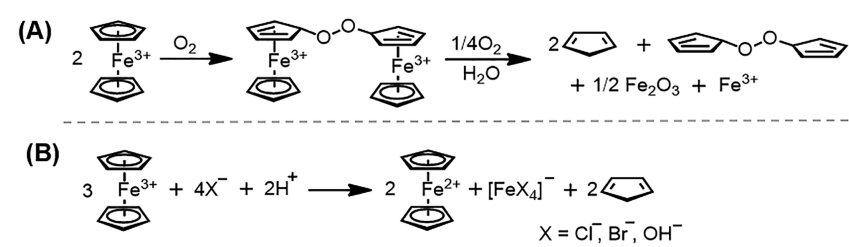

Figure 9. Possible side reactions of ferrocenium compounds: (A) oxygen oxidative degradation of ferrocenium; (B) ligand exchange pathway of ferrocenium degradation.

of ferrocenium by nucleophilic reagents through an irreversible ligand exchange reaction in organic solutions was also reported by Kortbeek in 1972. ${ }^{58}$ Because the ligand exchange reaction was coupled to a set of irreversible reduction reactions and $\mathrm{Cp}$ radical transformations, ferrocenium could be decomposed by weak donors such as $\mathrm{Cl}^{-}, \mathrm{Br}^{-}$, and $\mathrm{OH}^{-}$(Figure 9B). In the case of compounds 1 and 11, a Cp ligand was functionalized with an electron-withdrawing ammonium group, which would weaken the coordination of the $\mathrm{Cp}$ ligand to the $\mathrm{Fe}^{3+}$ center and result in the ligand exchange reaction. Meanwhile, ferrocene compounds are susceptible to strong acids and bases due to the protonation of the $\mathrm{Cp}$ ligand under acidic conditions and hydrolysis of $\mathrm{Fe}^{2+}$ or $\mathrm{Fe}^{3+}$ under basic conditions. 
In terms of the anode side, viologen molecules are highly attractive due to their high solubility in water, low cost, feasible synthetic tunability through $\mathrm{N}$-alkylation, fast electrochemical kinetics, and excellent chemical stability under $\mathrm{pH}$-neutral conditions. $^{35}$ In fact, viologen molecules can undergo two reductions, i.e., $[\mathrm{MV}]^{2+/+}$ and $[\mathrm{MV}]^{+/ 0}$ redox couples in the case of $[\mathrm{MV}]^{2+} \cdot{ }^{26}$ However, only the first $[\mathrm{MV}]^{2+/+}$ redox couple was initially utilized for energy storage because the second redox couple is not electrochemically reversible due to the insolubility of the charge-neutral $[\mathrm{MV}]^{0}$ in an aqueous solution. $^{26}$ In order to unlock the second electron storage capacity, Liu et al. designed viologen molecules with pendant propyl ammonium groups, $\left[(\mathrm{NPr}) \mathrm{MeV}^{-} \mathrm{Cl}_{3} \quad(16)\right.$ and $\left[(\mathrm{NPr})_{2} \mathrm{~V}\right] \mathrm{X}_{4}(\mathrm{X}=\mathrm{Br}$ or $\mathrm{Cl}, 17){ }^{26}$ The pendant ammonium groups enable the reversible second electron reduction of $[(\mathrm{NPr}) \mathrm{MeV}]^{3+}$ and $\left[(\mathrm{NPr})_{2} \mathrm{~V}\right]^{4+}$, which is not accessible by the simple $\mathrm{MV}^{2+}$. When paired with $\mathrm{FcNCl}(11)$, AORFBs of $[(\mathrm{NPr}) \mathrm{MeV}]^{3+}$ and $\left[(\mathrm{NPr})_{2} \mathrm{~V}\right]^{4+}$ achieve battery voltages of up to $1.39 \mathrm{~V}$ and theoretical energy densities of up to $75.9 \mathrm{Wh} / \mathrm{L}$. These AORFBs deliver good cycling stability up to $99.99 \%$ per cycle and impressive power densities of up to $130 \mathrm{~mW} / \mathrm{cm}^{2}$ even at $\mathrm{pH}$-neutral conditions (Figure $8 \mathrm{C}$ ). It is worth noting that these compounds are rare examples of two electron storage anode materials under $\mathrm{pH}$-neutral conditions.

Aziz et al. independently reported the synthesis and flow battery application of $\left[(\mathrm{NPr})_{2} \mathrm{~V}\right] \mathrm{Cl}_{4} \cdot{ }^{16}$ When coupled with a water-soluble ferrocene molecule, BMMAP-Fc (Figure 8B), the flow battery delivered very stable cycling stability, 99.9989\% per cycle for 500 cycles. It should be noted that the reported stability was obtained using two-stage charge/ discharge processes. First a galvanostatic process was used to gain a major battery capacity of ca. $7.0 \mathrm{Ah} / \mathrm{L}$, and then, a constant potential hold charge/discharge process was applied to gain an additional ca. $1.0 \mathrm{Ah} / \mathrm{L}$ to overcome the capacity loss caused by the increased membrane resistance.

Liu et al. studied the stability of $[\mathrm{MV}] \mathrm{Cl}_{2}$ and $\left[(\mathrm{NPr})_{2} \mathrm{~V}\right] \mathrm{Cl}_{4}$ using UV-vis spectroscopic and battery studies. ${ }^{50} \mathrm{UV}-$ vis spectroscopic studies provided direct experimental evidence of the improved radical stability of $\left[(\mathrm{NPr})_{2} \mathrm{~V}\right]^{3+\bullet}$ over $[\mathrm{MV}]^{+\bullet}$, suggesting that additional positively charged functional groups can stabilize the radical state. Combining $\left[(\mathrm{NPr})_{2} \mathrm{~V}\right] \mathrm{Cl}_{4}$ with $\mathrm{N}^{\mathrm{Me}}$-TEMPO, the newly designed $(\mathrm{NPr})_{2} \mathrm{~V} / \mathrm{N}^{\mathrm{Me}}-\mathrm{TEMPO}$ AORFB delivered significantly improved cycling stability, specifically, retaining $97.48 \%$ total capacity after 500 cycles, corresponding to $99.995 \%$ capacity retention per cycle (Figure $6 \mathrm{~B}){ }^{50}$ Under the same testing conditions, the $\mathrm{MV} / \mathrm{N}^{\mathrm{Me}}$ TEMPO AORFB retained only $91.21 \%$ of the total capacity after 500 cycles, corresponding to $99.982 \%$ capacity retention per cycle. It was previously reported that the charged state of viologen molecules, [Vio $]^{+\bullet}$, can undergo a bimolecular process to form a dimer called the viologen pimer (Figure 10A). ${ }^{59}$ The dimerization is believed to cause capacity fading in MV-based AORFBs. ${ }^{50}$ The pendant charged groups of $\left[(\mathrm{NPr})_{2} \mathrm{~V}\right] \mathrm{Cl}_{4}$ can mitigate the dimerization of the viologen radical and lead to the observed stable battery cycling performance (Figure 10A). In addition, with additional pendant ammonium groups, $\left[(\mathrm{NPr})_{2} \mathrm{~V}\right] \mathrm{Cl}_{4}$ showed much lower permeability $\left(6.7 \times 10^{-10} \mathrm{~cm}^{2} \mathrm{~s}^{-1}\right)$ in a Selemion DSV anion exchange membrane than $\operatorname{MVCl}_{2}\left(3.4 \times 10^{-9} \mathrm{~cm}^{2} \mathrm{~s}^{-1}\right)$, which is also beneficial for the stability of AORFBs. ${ }^{16}$

Similar to $\left[(\mathrm{NPr})_{2} \mathrm{~V}\right] \mathrm{Cl}_{4}$, bis-sulfonate-functionalized viologen, $(\mathrm{SPr})_{2} \mathrm{~V}(19)$, also delivered excellent cycling stability in AORFBs. ${ }^{17,40}$ Due to the negatively charged pendant sulfonate
(A)

Favorable Dimerization 9
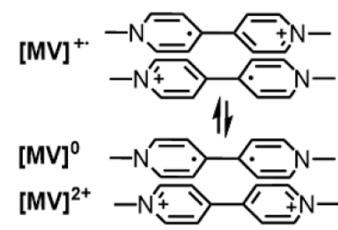

$[M V]^{0}+\mathrm{H}^{+} \longrightarrow[M V]^{++}+\mathrm{H}_{2} \uparrow$

(B)

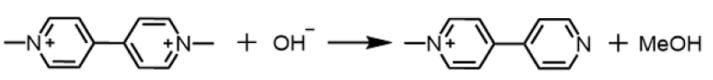

(C)

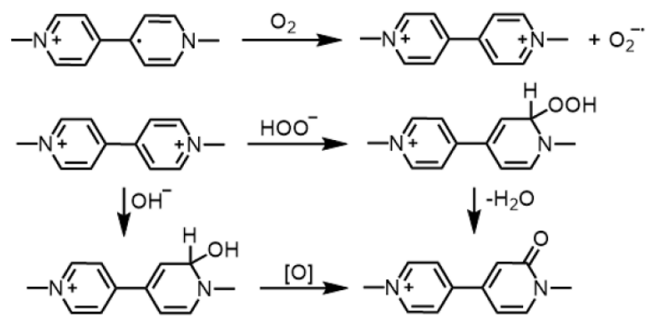

Figure 10. Possible side reactions of the viologen compounds: (A) proposed favorable dimerization of $[\mathrm{MV}]^{+\bullet}$ and unfavorable dimerization of $\left[(\mathrm{NPr})_{2} \mathrm{~V}\right]^{+\bullet}$ and $\left[(\mathrm{SPr})_{2} \mathrm{~V}\right]^{-\bullet}$ (the red double arrows indicate charge repulsion between the pendent ammonium groups) and the following chemical discharge of $[\mathrm{MV}]^{0}$ species; (B) dealkylation of $\mathrm{MV}^{2+}$ under alkaline conditions; (C) aerobic oxidation of $[\mathrm{MV}]^{+\bullet}$ and oxidative degradation of $\mathrm{MV}^{2+}$ in the presence of active oxygen species.

groups, the overall neutral-charged $(\mathrm{SPr})_{2} \mathrm{~V}$ is compatible with the cation-exchange membrane. Liu et al. paired it with lowcost inorganic $\mathrm{I}^{-}, \mathrm{Br}^{-51}$ and $\left[\mathrm{Fe}(\mathrm{CN})_{6}\right]^{4-17}$ catholytes for $\mathrm{pH}$-neutral AORFBs, which employ a cation charge exchange mechanism, different from other reported anion exchange viologen AORFBs. As shown in Figure $8 \mathrm{D}$, a symmetric $\mathrm{pH}$ neutral AORFB using a mixed electrolyte of $0.9 \mathrm{M}(\mathrm{SPr})_{2} \mathrm{~V}$ and $0.9 \mathrm{M}\left(\mathrm{NH}_{4}\right)_{4}\left[\mathrm{Fe}(\mathrm{CN})_{6}\right](24.1 \mathrm{Ah} / \mathrm{L})$ delivered nearly no capacity decay for 1000 cycles (1100 h testing duration), representing the most stable AORFB known to date, whose chemical stability was confirmed by postcell ${ }^{1} \mathrm{H}$ NMR, UVvis, and $\mathrm{CV}$ studies. ${ }^{17}$ The $(\mathrm{SPr})_{2} \mathrm{~V} / \mathrm{Br}^{-}$AORFB reported by the same group was operated at up to $1.5 \mathrm{M}$ concentration and an energy density of up to $30.4 \mathrm{Wh} / \mathrm{L}$. This battery delivered up to $78 \%$ energy efficiencies at $40 \mathrm{~mA} / \mathrm{cm}^{2}$ current density and $227 \mathrm{~mW} / \mathrm{cm}^{2}$ power density, the highest power density known for $\mathrm{pH}$-neutral AORFBs. ${ }^{51}$ In addition, it is worth noting that 2,2-bipyridinium recently demonstrated rather stable cycling performance. ${ }^{60}$ Regarding the mechanism of capacity fading through viologen dimerization, a chemical discharge pathway was proposed to explain the inferior stability of $[\mathrm{MV}]^{+\bullet}$ compared to that of $\left[(\mathrm{NPr})_{2} \mathrm{~V}\right]^{3+\bullet} \cdot 50$ The dimer of $[\mathrm{MV}]^{+}$is believed to further undergo a disproportionation reaction to give $[\mathrm{MV}]^{0}$ and $[\mathrm{MV}]^{2+}$ (Figure $10 \mathrm{~A}$ ). $[\mathrm{MV}]^{0}$ $\left(E_{1 / 2}\left(\mathrm{MV}^{+/ 0}\right)=-0.72 \mathrm{~V}\right.$ vs $\left.\mathrm{NHE}\right)$ is highly reductive and can react protons to produce $\mathrm{H}_{2}$ even at $\mathrm{pH}$, which eventually leads to the formation of $[\mathrm{MV}]^{2+}$. The chemical discharge of $[\mathrm{MV}]^{+\bullet}$ results in the charge imbalance between the anode (more discharged state) and cathode (more charged state) and thus causes the capacity decay of flow batteries. In the case of $\left[(\mathrm{NPr})_{2} \mathrm{~V}\right]^{3+\bullet}$, the dimer formation is kinetically unfavorable because of the repulsion effect of the pendant amine group. It should be noted that less negative redox potentials of 
(A)

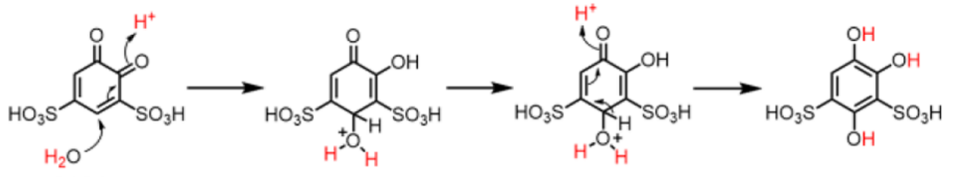

(B)

$$
\text { BQDS }
$$

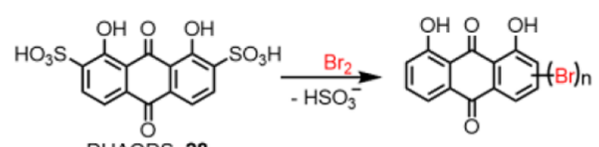

(C)

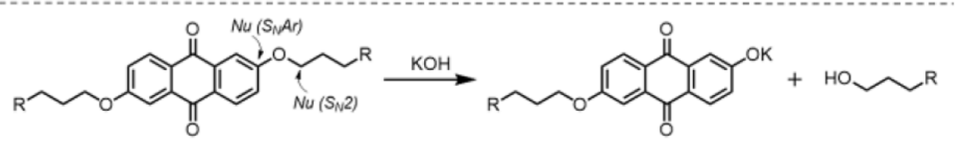

(D)

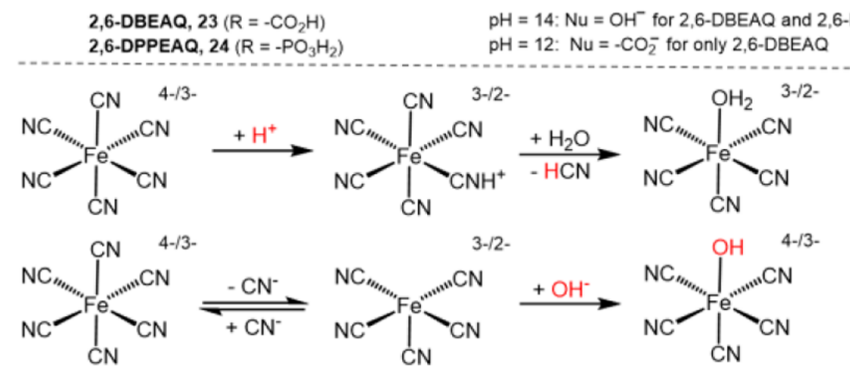

Figure 11. Possible side reactions of redox-active compounds in the presence of acid (A,D), bromine (B), and base (C,D).

$\left[(\mathrm{NPr})_{2} \mathrm{~V}\right] \mathrm{Cl}_{4}$ may also disfavor the dimerization and $\mathrm{H}_{2}$ formation.

Viologen molecules have been broadly applied as herbicides in agrochemistry, electrochromic materials, and redox mediators in electrochemical and photochemical studies. Other studies have investigated the possible degradation chemistry of viologens other than the dimerization chemical discharge in the past decades before their applications in flow batteries. Nucleophilic substitution of hydroxyl anion to the pyridinium under alkaline conditions to generate pyridine and methanol was reported (Figure 10B), ${ }^{61}$ which excludes the use of viologen compounds in strong alkaline flow batteries. Oxygen is another important factor that causes the decomposition of viologen compounds. Both reductive state viologen species $\left([\mathrm{Vio}]^{+\bullet}\right.$ and $\left.[\mathrm{Vio}]^{0}\right)$ are highly oxygen-sensitive. The reductive state of viologen reacts with oxygen to generate active oxygen species [O] that will directly react with viologen to cause the oxygenation of viologen (Figure 10C). ${ }^{62}$

Acidic AORFBs. Due to its smallest size and favorable Grotthus conductive mechanism, the proton shows the highest conductivity in both cation conductive membranes and water solutions among all cations, for example, $349.6 \mathrm{mS} /(\mathrm{mol} \cdot \mathrm{cm})$ for $\mathrm{H}^{+}$and $50.1 \mathrm{mS} /(\mathrm{mol} \cdot \mathrm{cm})$ for $\mathrm{Na}^{+}{ }^{63}$ Thus, with highly conductive acidic supporting electrolytes and proton exchange membranes, acidic AORFBs can deliver high charge/discharge rate performance, high energy efficiencies, and high power densities.

The first application of redox-active organic molecules in acidic AORFBs was reported by Wen et al. in $2009 .{ }^{64,65}$ This group reported the use of 4,5-dihydroxy-1,3-benzenedisulfonate (abbreviated BQDS (also called tiron, $E_{1 / 2}=0.65 \mathrm{~V}$ vs SCE) and 2,5-dihydroxybenzenedisulfonate (BQS, $E_{1 / 2}=0.47$ $\mathrm{V}$ vs SCE) as catholytes in acidic AORFBs where $\mathrm{PbSO}_{4}$ was used as the anolyte. The reported quinone/ $\mathrm{Pb}$ AORFB with a cell voltage of $0.92 \mathrm{~V}$ was only operated at a $50 \mathrm{mM}$ concentration $(1.34 \mathrm{Ah} / \mathrm{L})$ for 100 cycles. At $10 \mathrm{~mA} / \mathrm{cm}^{2}$, average Coulombic and energy efficiencies of up to 98 and $70 \%$, respectively, were achieved; however, the cycling stability was unknown. Like other RFBs involving a solid electrode $(\mathrm{Pb}$ anode in this case), the advantage of decoupled energy and power is eliminated. It is worth noting that the chemical decomposition mechanism of BQDS was presented. ${ }^{65}$ As displayed in Figure 11A, after the two-electron and twoproton-coupled oxidation of BQDS, in the formed charged state, 4,5-benzoquinone-1,3-benzenedisulfonate can undergo a Michael addition with water and result in the degraded product 3,4,5-tribenzohydroquinone-1,3-benzenedisulfonate, which is a stable species for battery cycling. Compared to BQDS, 3,4,5tribenzoquinone-1,3-benzenedisulfonate has a lower reduction potential at $E_{1 / 2}=0.48 \mathrm{~V}$ vs SCE. In contrast, BQS with its more electron-rich character does not undergo the Michael addition.

In 2014, Aziz et al. reported an organic-inorganic hybrid acidic AORFB employing 9,10-anthraquinone-2,7-disulfonic acid (AQDS, 25) in $1.0 \mathrm{M} \mathrm{H}_{2} \mathrm{SO}_{4}$ as an anolyte, a mixture of $0.5 \mathrm{M} \mathrm{Br}_{2}$ and $3 \mathrm{M} \mathrm{HBr}$ as a catholyte, and a Nafion 212 cation-exchange membrane as a separator. ${ }^{28}$ The AQDS $/ \mathrm{Br}^{-}$ AORFB delivered a $0.85 \mathrm{~V}$ battery voltage. Due to the high conductivity of the acidic system, the demonstrated AORFB delivered an exceptional peak power density exceeding $0.6 \mathrm{~W} /$ $\mathrm{cm}^{2}$.

However, when the AQDS/ $\mathrm{Br}^{-} \mathrm{AORFB}$ was cycled under a lower current density of $200 \mathrm{~mA} / \mathrm{cm}^{2}$, the average $\mathrm{CE}$ was dramatically decreased to $95 \%$, which was mainly due to the crossover of the charge-neutral $\mathrm{Br}_{2} .{ }^{66} \mathrm{Li}$ et al. carefully studied the crossover behavior of bromine species in the same flow battery. ${ }^{67}$ The $\mathrm{Br}_{2}$ crossover rate was measured as $0.11 \mathrm{mmol}$ $\mathrm{cm}^{-2} \mathrm{~h}^{-1}$ in the absence of an electric field and $0.3-0.4 \mathrm{mmol}$ $\mathrm{cm}^{-2} \mathrm{~h}^{-1}$ during battery cycling in a Nafion 212 membrane. When a thicker Nafion 115 membrane was used to mitigate the bromine crossover, the $\mathrm{CE}$ and cycling stability of AQDS $/ \mathrm{Br}^{-}$ AORFB were significantly improved. ${ }^{6}$ 

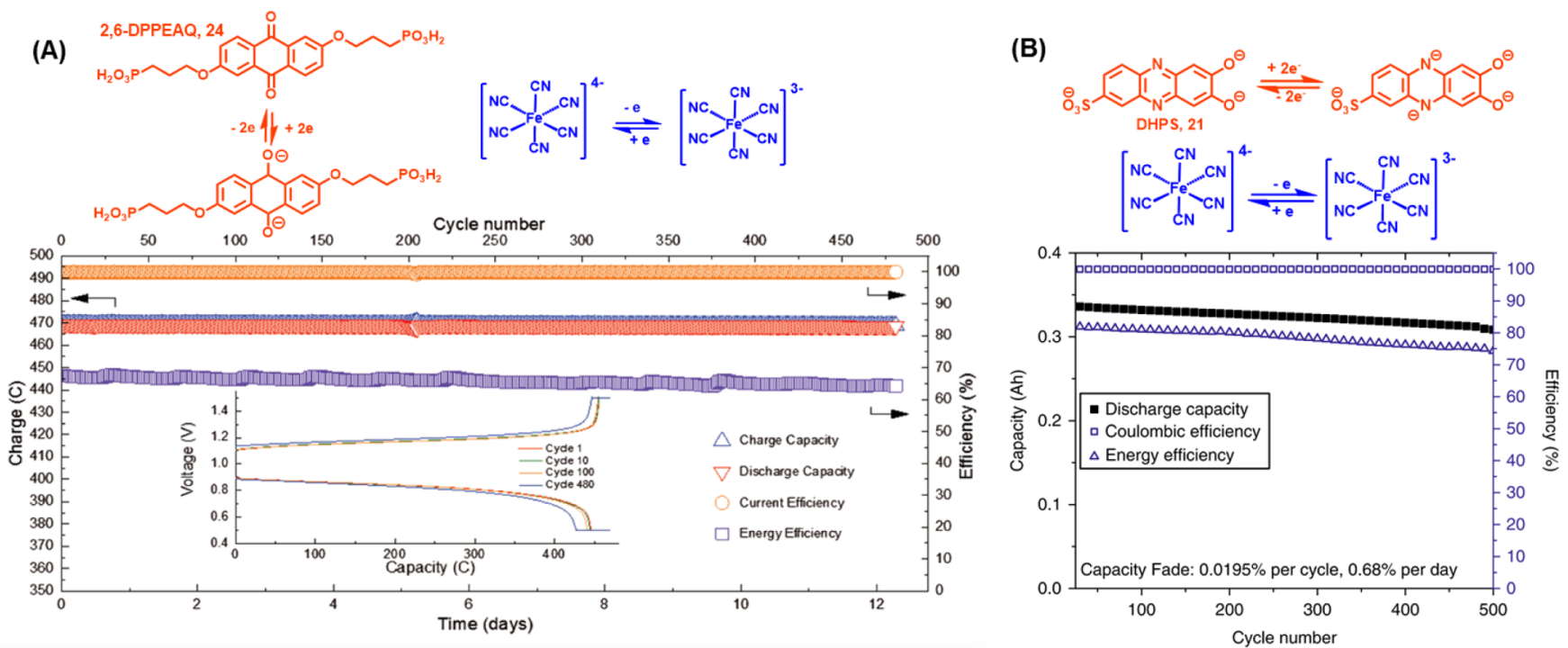

Figure 12. (A) Half-cell reactions and capacity and efficiency for the AORFB composed of 0.5 M 2,6-DPPEAQ anolyte and 0.4 M $\mathrm{K}_{4}\left[\mathrm{Fe}(\mathrm{CN})_{6}\right] / 0.1 \mathrm{M} \mathrm{K}_{3}\left[\mathrm{Fe}(\mathrm{CN})_{6}\right]$ catholyte at $100 \mathrm{~mA} / \mathrm{cm}^{2}$ current density. Inset: charge and discharge curves of selected cycles (adapted with the permission from Wiley). ${ }^{75}$ (B) Half-cell reactions and cycling data for the AORFB composed of $1.4 \mathrm{M}$ DHPS in $5 \mathrm{~mL}$ of $1 \mathrm{M}$ NaOH and $0.31 \mathrm{M} \mathrm{K}_{4}\left[\mathrm{Fe}(\mathrm{CN})_{6}\right] / 0.31 \mathrm{M} \mathrm{K}_{3}\left[\mathrm{Fe}(\mathrm{CN})_{6}\right]$ dissolved in $45 \mathrm{~mL}$ of $2 \mathrm{M} \mathrm{NaOH}$ cycled at a $100 \mathrm{~mA} / \mathrm{cm}^{2}$ current density (adapted with the permission from Springer Nature). ${ }^{76}$

Aziz et al. evaluated the chemical stability of AQDS with $\mathrm{Br}_{2} / \mathrm{HBr}$ mixtures using ${ }^{1} \mathrm{H}$ and ${ }^{13} \mathrm{C} \mathrm{NMR}{ }^{28}$ Even at $100{ }^{\circ} \mathrm{C}$ for $48 \mathrm{~h}$, no chemical degradation was observed for this discharged state. Furthermore, in a later half-cell study using AQDS and its charged state, $\mathrm{H}_{2} \mathrm{AQDS}$, slow capacity decay was observed and suggested good chemical stability of both AQDS and $\mathrm{H}_{2}$ AQDS in the acidic electrolyte. ${ }^{68}$ The half-cell study also indicates that the reduced state, $\mathrm{H}_{2} \mathrm{AQDS}$, has inferior stability. However, side reactions between the crossedover reactive bromine and redox molecules would result in the degradation of other anolytes. For example, the electrondonating aryl hydroxyl groups in the anthraquinone could activate parasitic bromination side reactions with bromine. ${ }^{27}$ As shown in Figure $11 \mathrm{~B}$, in the presence of bromine, DHAQDS, compound 27, was decomposed to polybrominated product by loss of sulfonic acid groups and addition of bromine to the aromatic rings. Recently, Brushett et al. studied concentration-dependent dimerization of compound 25 in the electrolytes under high concentration and different $\mathrm{pH}$ values. ${ }^{69}$ For example, in acidic electrolytes, the redox cycle between the semianthraquinone-anthraquinone dimer and the hydroxyanthraquinone dimer delivered a maximum capacity of only $1.5 \mathrm{M}$ electrons (out of $2.0 \mathrm{M}$ ) per 1.0 M AQDS.

In 2014, Narayanan et al. independently reported all organic quinone AORFBs using AQDS or AQS as the catholyte and BQDS as the anolyte in sulfuric acid supporting electrolytes. $^{44,70}$ These AQDS/BQDS and AQS/BQDS AORFBs $(0.2$ $\mathrm{M})$ delivered low cell voltages less than $0.6 \mathrm{~V}$ and limited cycling performance with a total capacity retention $(0.2 \mathrm{M}$ active material and $5.4 \mathrm{Ah} / \mathrm{L}$ ) of ca. $90.1 \%$ for 12 cycles. Later, the same group ${ }^{71}$ and other groups ${ }^{72}$ made efforts to develop highly substituted quinone molecules to overcome the stability issue of BQDS (Figure 11A). However, the battery performance of the substituted quinone catholytes is still not satisfactory. For example, 3,6-dihydroxy-2,4-dimethylbenzenesulfonic acid (DHDMBS) reported by Narayanan et al. is more stable than BQDS but only delivered $90 \%$ capacity retention after 25 cycles with an AQDS anolyte due to the crossover problem. $^{71}$ Other substituted quinone molecules are not chemically persistent enough. ${ }^{72}$

Alkaline AORFBs. Similar to the proton, the hydroxide anion, under the Grotthus conductive mechanism, shows the highest ion conductivity $(198.6 \mathrm{mS} /(\mathrm{mol} \cdot \mathrm{cm}))$ among all kinds of anions $^{63}$ and thus enables alkaline AORFBs to deliver good energy efficiencies and power densities. Aziz et al. reported alkaline AORFBs using 2,6-dihydroxyanthraquinone (2,6DHAQ 22) as the anolyte and $\mathrm{K}_{4}\left[\mathrm{Fe}(\mathrm{CN})_{6}\right]$ as the catholyte in $\mathrm{KOH}$ supporting electrolyte, which has a high OCV of 1.2 $\mathrm{V}, 47 \%$ over that of the acidic AQDS $/ \mathrm{Br}^{-}$AORFB. ${ }^{45}$ Under strong basic conditions, the $-\mathrm{OH}$ groups of 2,6-DHAQ are deprotonated to provide $>0.6 \mathrm{M}$ solubility. The demonstrated 2,6-DHAQ $/ \mathrm{K}_{4}\left[\mathrm{Fe}(\mathrm{CN})_{6}\right]$ AORFB delivered $84 \% \mathrm{EE}$ at 100 $\mathrm{mA} / \mathrm{cm}^{2}$ current density and $0.45 \mathrm{~W} / \mathrm{cm}^{2}$ power density at room temperature. However, the energy density of the 2,6$\mathrm{DHAQ} / \mathrm{K}_{4}\left[\mathrm{Fe}(\mathrm{CN})_{6}\right]$ system was limited by the low concentration of catholyte $\left(0.4 \mathrm{M}\right.$ solubility of $\mathrm{K}_{4}\left[\mathrm{Fe}(\mathrm{CN})_{6}\right]$ in $1 \mathrm{M} \mathrm{KOH})$. More recent studies by Aziz et al. have confirmed the insufficient stability of 2,6-DHAQ in strong alkaline conditions. ${ }^{68}$ They conducted ingenious molecular engineering of 2,6-DHAQ to develop two new derivatives, $4,4^{\prime}-((9,10$-anthraquinone-2,6-diyl $)$ dioxy $)$ dibutyrate $(2,6-$ DBEAQ 23 $)^{47}$ and $((9,10$-dioxo-9,10-dihydroanthracene2,6-diyl)bis(oxy))bis(propane-3,1-diyl))bis(phosphonic acid) (2,6-DPPEAQ 24). ${ }^{49}$ Paired with $\mathrm{K}_{4}\left[\mathrm{Fe}(\mathrm{CN})_{6}\right]$, 2,6-DPPEAQ delivered total capacity retention of 98.85 or $99.99964 \%$ capacity retention per cycle under weakly alkaline conditions $(\mathrm{pH} 9)$ (Figure 12A), which confirms the $\mathrm{pH}$ impact on the chemical stability of these anthraquinone molecules. ${ }^{49}$ It should be noted that the reported stability was obtained by using a hybrid galvanostatic/constant potential charge/ discharge method, which cannot be directly comparable with those obtained from the solo galvanostatic charge/discharge method. According to the inset figure in Figure 12A, after removing the secondary charging process using the potential control, the total capacity retention of the 2,6-DPPEAQ/ $\mathrm{K}_{4}\left[\mathrm{Fe}(\mathrm{CN})_{6}\right]$ was about $92.8 \%$ after 400 cycles, corresponding 
to $99.98196 \%$ capacity retention per cycle. As shown in Figure $11 \mathrm{C}$, under strong alkaline conditions $(\mathrm{pH}=14)$, a hydroxidemediated nucleophilic substitution reaction $\left(S_{N} A r\right.$ or $\left.S_{N} 2\right)$ dominates in the decomposition of both 2,6-DBEAQ and 2,6DPPEAQ. ${ }^{47}$ However, under less basic conditions $(\mathrm{pH}=12)$, carboxylate substituents lead to the nucleophilic decomposition of 2,6-DBEAQ whereas no intramolecular reaction of 2,6DPPEAQ is observed due to the weaker nucleophilicity of the bulky phosphonate group relative to carboxylate. ${ }^{49}$ Very recently, several AQ derivatives including AQDS $\left(\mathrm{NH}_{4}\right)_{2}(29)$ were also studied for $\mathrm{pH}$-neutral AORFBs and displayed promising cycling performance. ${ }^{73,74}$

A number of bioinspired phenazine molecules as another class of anolytes have been studied in alkaline AORFBs. ${ }^{46,76,77}$ Particularly, Wei and Wang et al. developed 7,8-dihydroxyphenazine-2-sulfonic acid (DHPS, 21 in Figure 2) featuring a high capacity and outstanding stability under alkaline conditions. ${ }^{76}$ An alkaline AORFB using a near-saturated DHPS anolyte $(1.4 \mathrm{M}$ in $1 \mathrm{M} \mathrm{NaOH})$ and a $\mathrm{K}_{4}\left[\mathrm{Fe}(\mathrm{CN})_{6}\right] /$ $\mathrm{K}_{3}\left[\mathrm{Fe}(\mathrm{CN})_{6}\right]$ catholyte delivered a $1.4 \mathrm{~V}$ voltage, up to a 67 $\mathrm{Ah} / \mathrm{L}$ reversible operating capacity for DHPS with $90 \%$ material utilization, $99.98 \%$ capacity retention per cycle, and $>75 \%$ EE for 500 charge/discharge cycles at $100 \mathrm{~mA} / \mathrm{cm}^{2}$ (Figure 12B). It is worth noting that computational and NMR studies revealed that the asymmetric molecular structure of DHPS is beneficial for its high solubility.

It should be noted that cathode materials suitable for alkaline AORFBs are very rare. Ferrocyanide $\left(\left[\mathrm{Fe}(\mathrm{CN})_{6}\right]^{4-}\right)$ is the most common catholyte used in the reported alkaline AORFBs. The chemical degradation of the ferri/ferrocyanide not only induces battery capacity fading but also is potentially hazardous. $^{78}$ The decomposition of the ferri/ferrocyanide anion under acidic conditions to generate extremely toxic $\mathrm{HCN}$ is well-known (Figure 11D). ${ }^{79}$ Liu et al. evaluated the cycling stability of the ferri/ferrocyanide redox couple under different $\mathrm{pH}$ values using a half-cell flow battery configuration. ${ }^{78}$ The battery results unambiguously confirmed that the ferri/ferrocyanide redox couple functions best at $\mathrm{pH}$ neutral or near-neutral conditions with very stable capacity retention observed. However, under strong alkaline conditions $(\mathrm{pH}=14)$, chemical decomposition of ferri/ferrocyanide was observed because of the ligand dissociation of the toxic $\mathrm{CN}^{-}$ (Figure 11D). In most of the previously reported strong alkaline AORFBs, an additional portion of ferricyanide in the ferri/ferrocyanide mixture catholyte was used to mask the battery capacity fading caused by the chemical degradation. ${ }^{45-48,76}$ In addition, the poor solubility of $\mathrm{K}^{+}$and $\mathrm{Na}^{+}$salts of ferri/ferrocyanide-based electrolytes limited the energy density of the RFBs. As mentioned above, ammonium ferri/ ferrocyanide as catholytes can achieve an effective charge capacity up to $42.89 \mathrm{Ah} / \mathrm{L}$, more than twice that of the $\mathrm{K}^{+}$and $\mathrm{Na}^{+}$salts. ${ }^{17}$

Chemistries of Nonaqueous Organic Redox Flow Batteries (NAORFBs). Aqueous electrolytes are limited by the narrow electrochemical window of water splitting, which is $1.23 \mathrm{~V}$ in terms of thermodynamics and can be extended up to $2.0 \mathrm{~V}$ considering kinetic barriers of the hydrogen evolution reaction (HER) and oxygen evolution reaction (OER) on carbon electrodes. Thus, the battery voltages of AORFBs are not more than $2.0 \mathrm{~V}$. In fact, the highest battery voltage reported up to now is $1.74 \mathrm{~V}$ for a viologen/TEMPO AORFB. ${ }^{26}$ In contrast, the nonaqueous system using organic solvents could enable a much wider potential range (up to $4.0 \mathrm{~V}$ ). Meanwhile, besides more choices of solvents, more redox-active organic molecules including those with a redox potential more negative than HER or more positive than OER can be used in organic solutions and allow more flexible battery designs. Because of these potential advantages, many efforts have been devoted to the development of redox-active molecules for nonaqueous ORFBs (NAORFBs). Up to now, many more organic compounds have been applied in NOARFBs than in AORFBs. Organic and organometallic compounds for NAORFBs include metallocene (both anolyte and catholyte), ${ }^{20,81-84}$ quinone (both anolyte and catholyte), ${ }^{43,85-88}$ dialkoxybenzene (catholyte), ${ }^{22,80,89-93}$ TEMPO (catholyte) and nitroxide radicals, ${ }^{94-100}$ viologen (both anolyte and catholyte), ${ }^{2,101,102}$ 4-benzoylpyridinium (anolyte), ${ }^{29,103}$ benzothiadiazole (anolyte), ${ }^{92} \mathrm{~N}$-methylphthalimide (anolyte), ${ }^{91}$ cyclopropenium (catholyte), ${ }^{37,104}$ 9-fluorenone (FL, anolyte), ${ }^{80}$ boron-dipyrromethene (bipolar), ${ }_{105}$ phenothiazine (catholyte), ${ }^{18}$ benzophenone (anolyte), ${ }^{106}$ quinoxaline (anolyte), ${ }^{89}$ and perylene diimide (anolyte). ${ }^{107}$ Other organometallic and coordination complexes were also reported as possible candidate electrolytes for NAORFBs. However, the development of NAORFBs is still in the infancy stage and lags much behind that of AORFBs. There are several major challenges associated with NAORFBs, including the lack of selective ion-exchange membranes in organic solutions, low conductivities of organic electrolytes, and safety concerns of flammable organic solvents. On the one hand, highly energetic free radicals (the charged state for both the anolyte and catholyte) are not chemically persistent and conceivably impact the cycling performance of NAORFBs. On the other hand, organic solvents and organic supporting electrolytes such as LiTFS and $\mathrm{Bn}_{4} \mathrm{NPF}_{6}$ can also undergo side reactions to endanger the battery cycling performance. ${ }^{108}$ It is obvious that flow battery chemistry in organic electrolytes is much more complicated than that in aqueous electrolytes. It is impossible to discuss all reported NAORFB chemistries in this short Review. We rather discuss representative examples with a focus on the fundamental understanding of physicochemical properties of organic molecules.

All-Organic NAORFBs. All-organic NAORFBs employ redoxactive organic compounds in organic solvents as anolytes and catholytes. $\mathrm{NaClO}_{4}$, LiTFSI, $\mathrm{LiPF}_{6}$, TEATFSI $($ TEA = tetraethylammonium cation), and $\mathrm{TBAPF}_{6}(\mathrm{TBA}=$ tetrabutylammonium cation) with high solubility in organic solvents are normally used as supporting electrolytes. Typical organic solvents with wide stable electrochemical windows are used in NAORFBs, including carbonates, DMSO, $\mathrm{CH}_{3} \mathrm{CN}$, and DME.

RFBs in organic solvents were first reported using $\mathrm{Ru}$ trisbipyridine coordination compounds by Matsuda et al. ${ }^{109}$ and later using other metal-based coordination compounds by Thompson, Byon, and others. ${ }^{110-115}$ The first demonstration of all-organic NOARFBs was reported using a TEMPO catholyte and an $\mathrm{N}$-methylphthalimide anolyte in a $1.0 \mathrm{M}$ $\mathrm{NaClO}_{4}$ in $\mathrm{CH}_{3} \mathrm{CN}$ supporting electrolyte. ${ }^{116}$ The TEMPO/ $\mathrm{N}$-methylphthalimide NAORFB has a cell voltage of $1.6 \mathrm{~V}$. A $0.1 \mathrm{M}$ flow battery using a Nepem-117 cation-exchange membrane demonstrated modest cycling performance for 20 cycles with a CE of $90 \%$, suggesting the crossover of active materials. No other battery data and postcell spectroscopic studies were reported.

Wei et al. systemically studied the radical compatibility of the 2,5-ditert-butyl-1-methoxy-4-[2'-methoxyethoxy] benzene (DBMMB) and FL through electron spin resonance (ESR) measurements. ${ }^{80}$ They compared the lifetime of both 

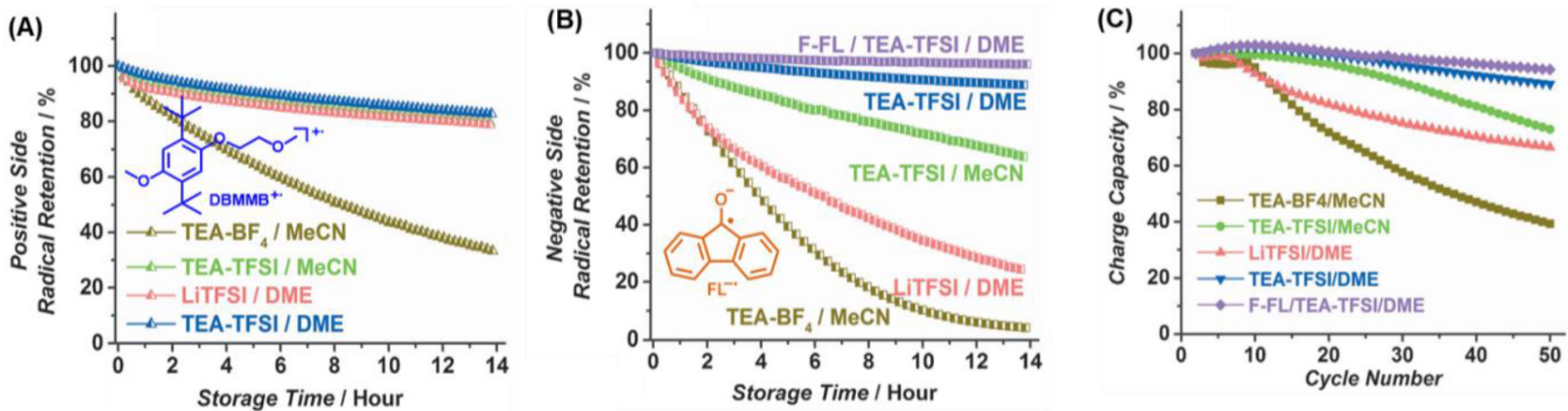

Figure 13. ESR-measured radical fading in various supporting electrolytes: $(\mathrm{A})$ positive side $\left(\mathrm{DBMMB}^{\bullet+}\right)$ and $(\mathrm{B})$ negative side $\left(\mathrm{FL}^{\bullet-}\right) .(\mathrm{C})$ Effects of different solvents and salts on charge capacity retention of flow cells using $0.1 \mathrm{M} \mathrm{FL} / 0.1 \mathrm{M} \mathrm{DBMMB} / 1.0 \mathrm{M} \mathrm{salt}$ at $10 \mathrm{~mA} \mathrm{~cm}^{2}$ (adapted with the permission from Wiley). ${ }^{80}$

(A)

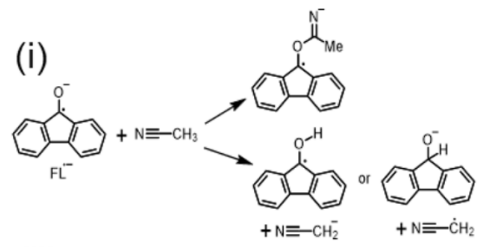

(ii)

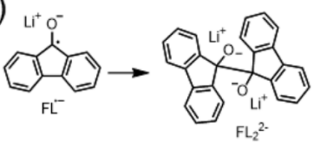

(B)

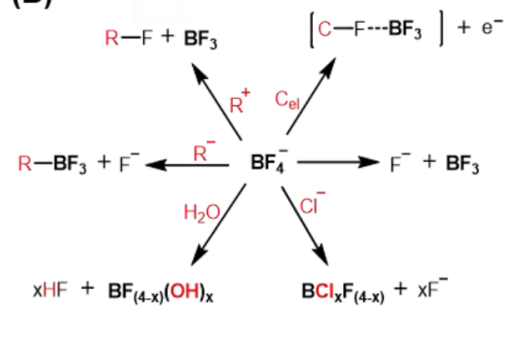

(C)

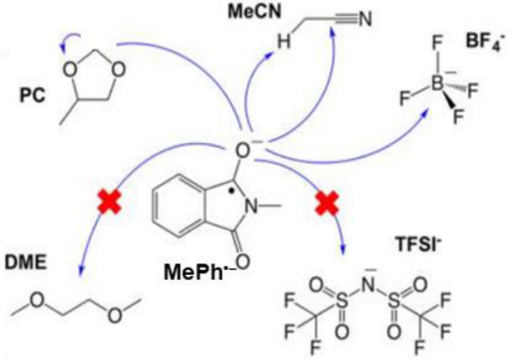

Figure 14. Possible degradation mechanisms of the $(\mathrm{A}) \mathrm{FL}^{\bullet-}$ radical anion (adapted with the permission from Wiley), ${ }^{80}(\mathrm{~B}) \mathrm{BF}_{4}^{-}$anion, and (C) $\mathrm{MePh}^{\bullet-}$ radical anion (adapted with permission from the American Chemical Society). ${ }^{11}$

$\mathrm{DBMMB}^{\bullet+}$ and $\mathrm{FL}^{\bullet-}$ radical ions in different solvents and supporting electrolytes (Figure 13A,B). DBMMBC ${ }^{\bullet+}$ showed good stability in all of the tested media except the $\mathrm{TEABF}_{4}$ supporting electrolyte. However, the $\mathrm{FL}^{\bullet-}$ radical stability was sensitive to both solvents and supporting electrolytes. For example, the $\mathrm{FL}^{\bullet-}$ radical showed a lower stability in the presence of $\mathrm{MeCN}$ solvent, $\mathrm{Li}^{+}$cation, and $\mathrm{BF}_{4}{ }^{-}$anion than other tested conditions. In the optimized TEA-TFSI/DME supporting electrolyte, both $\mathrm{DBMMB}^{\bullet+}$ and $\mathrm{FL}^{\bullet-}$ displayed the highest stability. Using a Daramic microporous membrane as a separator, a $0.1 \mathrm{M} \mathrm{FL/DBMMB}$ all-organic NAORFB was operated under $>10 \mathrm{~mA} / \mathrm{cm}^{2}$ current density for 50 cycles with $>70 \% \mathrm{EE}$ and $99.8 \%$ capacity retention per cycle (Figure 13C). It should be noted that to minimize crossover through the porous separator a mixture of FL and DBMMB was used as both the catholyte and anolyte, which is commonly used in other NAORFBs. As shown in Figure 14A(i), the side reaction between the $\mathrm{FL}^{\bullet-}$ radical and $\mathrm{MeCN}$ solvent could be either a nucleophilic addition reaction at the cyano $\mathrm{C}$ atom, proton extraction, or hydrogen atom absorption at the methyl group of $\mathrm{MeCN}$. The radical coupling dimerization catalyzed by the $\mathrm{Li}^{+}$cation is also a possible degradation pathway (Figure $14 \mathrm{~A}(\mathrm{ii}))$. Previous studies reported the decomposition of the $\mathrm{BF}_{4}^{-}$anion in the presence of other anions, cations, and $\mathrm{H}_{2} \mathrm{O} .^{108}$ It was proposed that $\mathrm{BF}_{4}^{-}$may cause the fast fading of $\mathrm{DBMMBC}^{\bullet+}$ and $\mathrm{FL}^{\bullet-}$ radicals (Figure 14B). Another example of organic radical compatibility in NAORFBs reported by Wei et al. is shown in Figure 14C. ${ }^{91}$ The side reactions between the $\mathrm{MePh}^{\bullet-}$ radical anion and solvents including acetonitrile $(\mathrm{MeCN})$, propylene carbonate (PC), cyclopropenium, or tetraethylammonium tetrafluoroborate $\left(\mathrm{TEABF}_{4}\right)$ led to substantial capacity fading of the $\mathrm{MePh} / \mathrm{DBMMB}$ battery.
Sanford et al. have also made efforts to develop highperformance organic redox molecules with low molecular weight and high stability by understanding their stabilities under different oxidation states. For example, they reported that steric hindrance enables improved radical stability of the acylpyridinium compound (10) than less substituted derivatives (Figure 15). ${ }^{25}$ They also reported that the Lewis acidity of cations of supporting electrolyte salts can impact the stability of acylpyridinium derivatives. ${ }^{29}$ Specifically, they found that the radical state of acylpyridinium is more

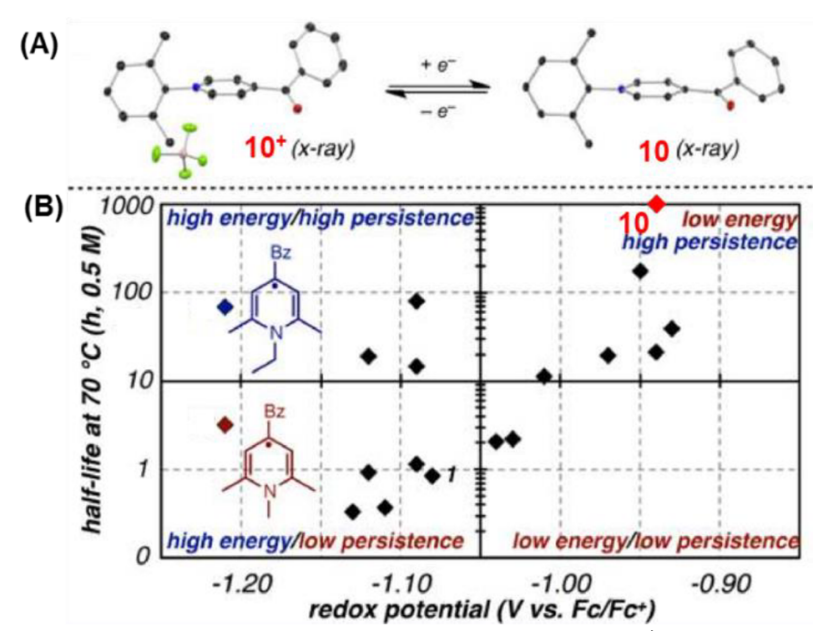

Figure 15. (A) X-ray structures of compounds $10^{+}$and 10. (B) Quadrant diagram of the radical half-life as a function of the redox potential (adapted with the permission from the American Chemical Society). ${ }^{25}$ 
(A)
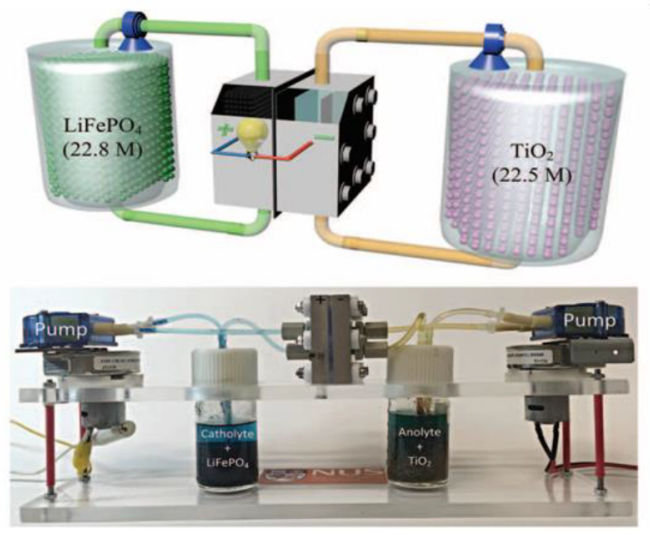

(C)

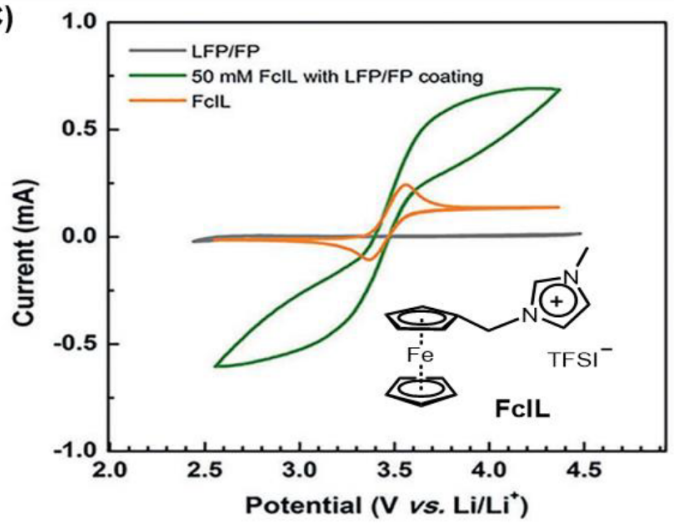

(B)

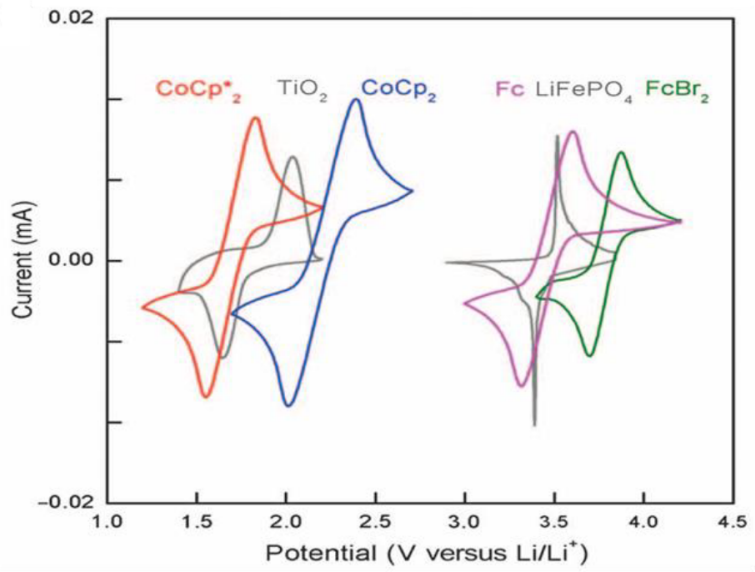

(D)

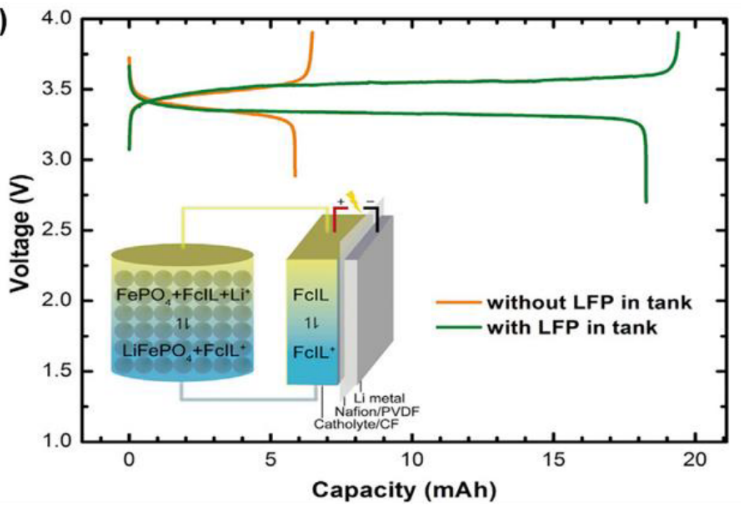

Figure 16. (A) Configuration of a $\mathrm{TiO}_{2} / \mathrm{LiFePO}_{4} \mathrm{RT}$-FB; (B) CV curves of organic mediators and solid electrode materials in the $\mathrm{TiO}_{2} /$ $\mathrm{LiFePO}_{4}$ RT-NAORFB (adapted with the permission from AAAS); ${ }^{121}$ (C) CV curves of the FcIL mediator and the solid electrode material (LFP) with and without FcIL; and (D) charge/discharge curves of the $\mathrm{Li} / \mathrm{LiFePO}_{4} \mathrm{RT}$-FB and the battery configuration (adapted with the permission from Elsevier). ${ }^{122}$

compatible with $\mathrm{KPF}_{6}$ than $\mathrm{LiPF}_{6}$ and $\mathrm{NaPF}_{6}$ as $\mathrm{K}^{+}$with its lower Lewis acidity will not induce Lewis acid/base degradation occurring with $\mathrm{Li}^{+}$and $\mathrm{Na}^{+}$.

To avoid the crossover of active materials, two other strategies have been developed. Extended from the use of mixed electrolytes, bipolar redox-active molecules have been developed for NAORFBs. Wei et al. reported a nitroxyl compound, 2-phenyl-4,4,5,5-tetramethylimidazoline-1-oxyl-3oxide (PTIO), with two redox couples at $-1.26 \mathrm{~V}$ (vs $\mathrm{AgCl} /$ $\mathrm{Ag}$ ) for the anode side and at $0.46 \mathrm{~V}$ for the cathode side. ${ }^{99}$ However, both 0.1 and $0.5 \mathrm{M}$ PITO NAORFBs at $20 \mathrm{~mA} / \mathrm{cm}^{2}$ delivered poor cycling stability with nearly $50 \%$ capacity loss within 35 cycles. Other bipolar molecules consisting of two distinct redox moieties were also reported by Schubert et al. ${ }^{117}$ and other groups. ${ }^{118}$ However, their battery performance is not satisfactory, with poor stability within limited cycling numbers even at low concentrations of active molecules less than $0.3 \mathrm{M}$. Another approach is called size exclusion, where larger size molecules, including oligomers and polymers, are designed to prevent their crossover through a porous separator. ${ }^{36,39,101,119}$ For example, Rodríguez-López et al. reported viologen- and ferrocene-containing polymers exhibited low permeabilities with Celgard separators. ${ }^{101,119}$ Helms and Sanford groups employed nanoporpous PIM separators to achieve low crossover with designed pyridinium and cyclopropenium oligomers (Figure 4). ${ }^{36,37}$ However, redox-active oligomers and polymers using the size exclusion principle are yet to be demonstrated for reliable battery performance.
Organic-Metal NAORFBs. Organic-metal NAORFBs are semiflow batteries that, typically, employ electrochemically active metals (such as $\mathrm{Li}$, and $\mathrm{Al}$ ) as static anodes and soluble organic molecules as flowable catholytes. Because of highly energy dense metal anodes and their low redox potential, the organic-metal NAORFBs can achieve high voltages and energy densities.

Wang et al. reported the first organic-metal NAORFB using an anthraquinone catholyte and a $\mathrm{Li}$ anode. ${ }^{85}$ They designed 1,5-bis(2-(2-(2-methoxyethoxy)ethoxy)ethoxy)anthracene9,10-dione (15D3GAQ) with two redox waves at 2.25 and 2.53 $\mathrm{V}$ vs $\mathrm{Li}$, which contains two glyme substituents to achieve good organic solubility up to $0.25 \mathrm{M}$ in a $1.0 \mathrm{M} \mathrm{LiPF}_{6} / \mathrm{PC}$ electrolyte. A $0.25 \mathrm{M}$ 15D3GAQ-Li NAORFB with a cell voltage of $2.39 \mathrm{~V}$ and a high energy density of $25 \mathrm{Wh} / \mathrm{L}$ was demonstrated for only nine cycles. Subsequently, other organic and organometallic compounds were studied in organic- $\mathrm{Li}$ NAORFBs. Particularly, ferrocene molecules have received intensive studies in Li metal NAORFBs. Yu et al. investigated ferrocene as a catholyte with a $\mathrm{Li}$ metal anode in a static battery configuration, which delivered reliable battery performance. $^{82}$ In order to overcome the solubility limitation of ferrocene and achieve high energy densities, Wang et al. developed a highly soluble ionic ferrocene compound, $\mathrm{Fc}_{1} \mathrm{~N}_{112^{-}}$ TFSI (compound 1) using a molecular engineering strategy. ${ }^{20}$ Using a carefully formulated supporting electrolyte to form a stable SEI and a hybrid $\mathrm{Li}$-graphite anode to suppress $\mathrm{Li}$ dendrite formation, a $3.5 \mathrm{~V} \mathrm{Li} / \mathrm{Fc}_{1} \mathrm{~N}_{112}$-TFSI flow cell with 0.8 
M compound 1 was successfully demonstrated for 18 cycles under a $1.5 \mathrm{~mA} / \mathrm{cm}^{2}$ current density with an EE of $76 \%$.

To improve the energy density of organic-Li NAORFBs, ideally, one should maximize redox-active components and minimize redox-inactive components such as solvents. Recently, several groups including Lu et al., Hase et al., and Zhang et al. developed low-melting-point liquid $\mathrm{Fc}$ derivative (DMFc, compound 2), ${ }^{81}$ TEMPO derivative (MT), ${ }^{96}$ and dialkoxybenzene derivatives (e.g., ANL-9, compound 7) 22 as cathode materials that can partly or totally replace the redoxinactive solvent. Under high concentrations of redox compounds, the capacity of electrolytes was controlled by the solubility of supporting electrolytes. It is still challenging to achieve good cycling stability for the $\mathrm{Li}$ semiflow batteries. While no in-depth mechanistic study was reported, it is believed that, in addition to the chemical stability of organic catholytes, the high reactivity, SEI formation, and dendrite formation of Li metal present major challenges. ${ }^{120}$

Redox-Targeting NAORFBs (RT-NAORFBs). Wang et al. proposed the concept of redox-targeting FBs that employing the so-called "redox-targeting reactions" to overcome the solubility limitation of redox-active materials. ${ }^{123}$ In redoxtargeting RFBs (Figure 16A), traditional solid-state $\mathrm{Li}^{+}$ion storage materials, such as $\mathrm{LiFePO}_{4}$ and $\mathrm{LiTiO}_{2}$, are employed as energy storage materials, and diluted solutions of redoxactive molecules are used as redox mediators to catalyze the charge/discharge of the solid electrode materials. The redox potential of $\mathrm{a} \mathrm{Li}^{+}$ion storage material needs to be sandwiched between those of two mixed mediators ${ }^{124,125}$ or ideally overlapped with that of a single mediator. ${ }^{122}$ The mediator solutions are pumped through the battery chamber, and the redox reactions happen within the flow cell. When the electrolytes flow back to the tanks, the reduced or oxidized mediators react with the solid energy storage materials and result in their charge/discharge. Then, the energy density of the battery system is independent of the solubility of redoxactive materials. Due to the high charge densities and stability of $\mathrm{Li}^{+}$ion storage materials, the redox-targeting $\mathrm{RFBs}$ can achieve superior energy density and stable cycling performance.

As shown in Figure $16 \mathrm{~A}, \mathrm{~B}$, in a $\mathrm{TiO}_{2} / \mathrm{LiFePO}_{4} \mathrm{RT}$ NAORFB, the anode material $\mathrm{TiO}_{2}\left(\sim 1.55 \mathrm{~V}\right.$, vs $\left.\mathrm{Li} / \mathrm{Li}^{+}\right)$ was mediated by the mixture of cobaltocene $\left(\mathrm{CoCp}_{2}, 1.90 \mathrm{~V}\right)$ and decamethylcobaltocene $\left(\mathrm{CoCp}_{2}, 1.36 \mathrm{~V}\right) .{ }^{124}$ Specifically, during the charge process, $\left[\mathrm{CoCp} *_{2}\right]^{+}$is first reduced in the cell, and then, the reduced state, $\mathrm{CoCp}{ }_{2}$, flows into the $\mathrm{TiO}_{2}$ anode reservoir to reduce $\mathrm{TiO}_{2}$. The regenerated $\left[\mathrm{CoCp} *_{2}\right]^{+}$ will flow back to the cell chamber and be reduced until $\mathrm{TiO}_{2}$ is fully charged. During the discharge process, the redox couple of $\left[\mathrm{CoCp}_{2}\right]^{+/ 0}$ will be cycled to oxidize the charged $\mathrm{TiO}_{2}$. In a similar manner, the change/discharge of the $\mathrm{LiFePO}_{4}(\sim 3.45$ $\mathrm{V})$ cathode was mediated by $\mathrm{Fc}(3.25 \mathrm{~V})$ and $1,1^{\prime}$ dibromoferrocene $\left(\mathrm{FcBr}_{2}, 3.55 \mathrm{~V}\right)$. The demonstrated battery delivered a $\sim 1.25 \mathrm{~V}$ average discharge voltage and $\sim 238 \mathrm{Wh} / \mathrm{L}$ energy density under a $0.075 \mathrm{~mA} / \mathrm{cm}^{2}$ operating current density. However, due to the redox potential differences in each set of organic mediators and $\mathrm{Li}^{+}$ion storage materials, there was a $1.05 \mathrm{~V}$ voltage loss of the theoretical voltage of the $\mathrm{TiO}_{2} / \mathrm{LiFePO}_{4} \mathrm{RT}$-NAORFB. To avoid the voltage loss of the RT-NAORFBs, Wang et al. recently developed an imidazolium-functionalized ferrocene ionic liquid (FcIL) with an identical redox potential to the solid electrode material and applied it as a single redox mediator to catalyze the charge/ discharge of $\mathrm{LiFePO}_{4}$ (Figure 16C). ${ }^{122}$ With the driving force of the Nernstian potential difference induced by activity changes of the redox molecules upon charging and discharging, $\mathrm{LiFePO}_{4}$ was reversibly delithiated and lithiated under nearunity utilization. As a result, the $\mathrm{Li} / \mathrm{LiFePO}_{4} \mathrm{RT}-\mathrm{NAORFB}$ delivered 95\% VE and a $330 \mathrm{Wh} / \mathrm{L}$ energy density (Figure 16D). The redox-targeting RFB concept was recently further introduced into $\mathrm{Li}-\mathrm{S}$ and $\mathrm{Li}-\mathrm{O}_{2}$ battery systems and aqueous systems. $^{126,127}$

Summary and Outlook. Currently, the electrochemical performance of AORFBs holds promise for practical energy storage applications. As discussed above, acidic and alkaline AORFBs have delivered better current performance, energy efficiencies, and power densities than the $\mathrm{pH}$-neutral AORFBs; however, the redox-active materials in the acidic and alkaline AORFBs are subject to stability problems. Besides the acid/ base induced redox-active material degradation, HER and OER can easily take place under strong acidic and basic conditions, respectively. These side reactions would lead to the imbalance of charge between the anolyte and catholyte and manifest irreversible CE loss and capacity decay. In terms of battery performance and system cost, $\mathrm{pH}$-neutral AORFBs are highly promising for large-scale EES. Weakly alkaline AORFBs can also be promising if suitable catholytes can be developed in the future. It is worth noting that a number of AORFBs and also AIRFBs have been integrated with solar cells for direct solar energy harvesting and storage. ${ }^{128-134}$

NAORFBs can achieve high battery voltages; however, they are still in the early stage of development, with several major challenges. First, due to the chemical degradation and crossover of redox molecules, the cycling performance of NAORFBs is much worse than that of AORFBs. Even some redox-active materials displayed high solubility; however, only low concentrations were showcased in battery demonstration. High-energy-density NAORFB systems with good cycling stability still remain to be developed. Thus, mechanistic understandings of chemical degradation of redox-active molecules and other components are critical to develop robust NAORFB electrolytes. Second, because of low conductivities and high viscosities of nonaqueous electrolytes, achieving high current and power densities in NAORFBs is challenging. We believe that NAORFBs are more suitable for long-term (days to weeks) energy storage where high current and high power performance are not demanded. Third, to minimize redox material crossover, using redox-active polymers or oligomers as electrolyte materials and developing highly selective ionconductive membranes are promising solutions.

To further develop ORFBs and make them practical, there are several pieces of advice regarding the future directions of ORFBs. First, robust redox molecules and electrolytes are demanded for high-performance ORFBs. The ideal redox molecules for ORFB application should have high solubility (increasing capacity and energy density), highly positive or negative redox potentials (increasing voltage, energy density, and power density), fast kinetics (increasing voltage and power density), high stability (increasing cycling lifetime), and low cost. These properties affect the performance of batteries in all aspects (Figure 1B). High-throughput DFT computation, physical organic studies, and molecular engineering are effective strategies for molecular designs. In term of redoxactive electrolytes, the ideal ones should be highly conductive, be less viscous, be noncorrosive, be nonflammable, have low toxicity, and be inexpensive. Future studies need comprehen- 


\section{Future studies need comprehensive consideration of the physical and chemical properties of both redox- active molecules and electrolytes to achieve high energy densities, high power densities, and high stability for ORFBs.}

sive consideration of the physical and chemical properties of both redox-active molecules and electrolytes to achieve high energy densities, high power densities, and high stability for ORFBs.

Second, in-depth understandings of the solution chemistry and electrochemistry of redox-active molecules and their electrolytes are necessary. As discussed above, it will provide useful information to guide further optimization of flow battery systems and feedback for improved molecular designs. Half-cell RFB tests are a direct and efficient method to evaluate the stability of a single redox molecule. ${ }^{68,78}$ Because both sides of the battery use the same redox couple, the capacity fading can be enlarged. The postcycling analysis can be used to detect capacity fading mechanisms. Except for these experimental methods, DFT computation is also a powerful tool for exploring the physicochemical information on redox-active molecules.

Moreover, highly selective ion-conductive membranes are urgently needed by RFBs, especially for nonaqueous systems. Actually, the active material crossover is one of the most important reasons for the capacity decay of NAORFBs. It is clear that the lack of selective ion-conductive membranes has become a bottleneck for the development of NAORFBs. Meanwhile, the design of flow cells also needs to be improved. There are several battery designs reported; however, no parallel comparison has been made for how electrode designs affect the EE and power density. Strictly speaking, directly comparing the battery performance data, especially the rate performance, energy efficiencies, and power densities delivered by different battery designs, is not reliable.

Compared to inorganic redox materials, the organic redox materials have a number of technological merits, including unlimited candidates in terms of the unlimited design space of organic molecules, highly tunable structure and properties, deep mechanistic studies, and potentially low prices and sustainability. It should be noted that, from a perspective of material cost, we also encourage the $\mathrm{R} \& \mathrm{D}$ of low-cost redoxactive inorganic materials (e.g., $\mathrm{FeCl}_{2}$ and $\mathrm{ZnBr}_{2}$ ) for $\mathrm{RFB}$ practices. During the past decade, significant progress was made for the development of ORFBs in both aqueous and nonaqueous systems. ORFBs are still in the early stage of technological development and need more $R \& D$ efforts and investments for industrial acceptance and broad implementation for energy storage.

\section{AUTHOR INFORMATION}

\section{Corresponding Author}

*E-mail: Leo.Liu@usu.edu.

\section{ORCID}

T. Leo Liu: 0000-0002-3698-1096

Notes

The authors declare no competing financial interest.

\section{Biographies}

Jian Luo received his Ph.D from the Fujian Institute of Research on the Structure of Matter, Chinese Academy of Sciences (FJIRSM, CAS). He is currently a postdoctoral fellow in Prof. Liu's group at Utah State University. His research expertise includes energy conversion and storage, electrochemical catalysis, and organic methodology.

Bo Hu received his Master's degree at Harbin Institution of Technology in China. He is now a fourth year graduate student with Ph.D. candidacy under the supervision of Professor Liu at Utah State University. His research mainly focuses on redox flow batteries and electrocatalysis.

Maowei Hu received her Master's degree from Dalian University of Technology. She is a first year graduate student in Prof. Liu's group at Utah State University. Her research includes redox flow batteries and electrocatalysis.

Yu Zhao received his Ph.D from Dalian University of Technology. He is an assistant professor at Ocean University of China. He is a visiting professor in Prof. Liu's group. His research expertise includes photocatalysts and fine chemicals.

Tianbiao Leo Liu received his Ph.D. from Texas A\&M University in 2009 and is an assistant professor at Utah State University. His research interests include energy storage, electrocatalysis, and green chemistry. He was recognized by a number of honors, including a 2015 ACS Catalysis Lectureship, 2017-2019 RCSA Scialog Fellow, and 2019 NSF Career Award.

\section{ACKNOWLEDGMENTS}

We are grateful for the funding support for our RFB research from the National Science Foundation (Career Award, Grant No. 1847674), a Utah State University Faculty start-up, the Utah Science Technology and Research initiative (USTAR) research award, the Utah Energy Triangle Faculty Award sponsored by the Utah State government, and the Scialog Innovative Award cofunded by the Sloan Foundation and Research Corporation on Science Advancement. B.H., M.H., and Y.Z. are grateful for a China CSC Abroad Studying Fellowship to support their Ph.D. or exchange study program at Utah State University.

\section{REFERENCES}

(1) Dunn, B.; Kamath, H.; Tarascon, J.-M. Electrical Energy Storage for the Grid: A Battery of Choices. Science 2011, 334 (6058), 928935

(2) Yang, Z.; Zhang, J.; Kintner-Meyer, M. C. W.; Lu, X.; Choi, D.; Lemmon, J. P.; Liu, J. Electrochemical Energy Storage for Green Grid. Chem. Rev. 2011, 111 (5), 3577-3613.

(3) Soloveichik, G. L. Flow Batteries: Current Status and Trends. Chem. Rev. 2015, 115 (20), 11533-11558.

(4) DOE. International Energy Outlook 2016, With Projections To 2040; U.S. Energy Information Administration (EIA), DOE/EIA0484, 2016.

(5) DOE. Revolution...Now: The Future Arrives for Five Clean Energy Technologies-2016 Update. Depertment of Energy. http://bit.ly/ 2hTv1WG (2016).

(6) Thaller, L. H. US3996064, 1976.

(7) Hu, B.; Luo, J.; Debruler, C.; Hu, M.; Wu, W.; Liu, T. L., RedoxActive Inorganic Materials for Redox Flow Batteries. In Ency. Inorg. Bioinorg. Chem.; 2019; pp 1 DOI: 10.1002/ 9781119951438.eibc2679.

(8) Wang, W.; Luo, Q.; Li, B.; Wei, X.; Li, L.; Yang, Z. Recent Progress in Redox Flow Battery Research and Development. Adv. Funct. Mater. 2013, 23 (8), 970-986. 
(9) Viswanathan, V.; Crawford, A.; Stephenson, D.; Kim, S.; Wang, W.; Li, B.; Coffey, G.; Thomsen, E.; Graff, G.; Balducci, P.; KintnerMeyer, M.; Sprenkle, V. Cost and performance model for redox flow batteries. J. Power Sources 2014, 247 (0), 1040-1051.

(10) DOE Office of ARPR-E. ARPA-E GRIDS Program Overview. http://arpa-e.energy.gov/sites/default/files/documents/files/ GRIDS_ProgramOverview.pdf (2011).

(11) Office of Electricity Delivery \& Energy Reliability, Depertment of Energy. Program Planning Document on Energy Storage. http:// energy.gov/oe/downloads/energy-storage-program-planningdocument-2011 (2011).

(12) Leung, P.; Shah, A. A.; Sanz, L.; Flox, C.; Morante, J. R.; Xu, Q.; Mohamed, M. R.; Ponce de León, C.; Walsh, F. C. Recent Developments in Organic Redox Flow Batteries: A Critical Review. J. Power Sources 2017, 360, 243-283.

(13) Wei, X.; Pan, W.; Duan, W.; Hollas, A.; Yang, Z.; Li, B.; Nie, Z.; Liu, J.; Reed, D.; Wang, W.; Sprenkle, V. Materials and Systems for Organic Redox Flow Batteries: Status and Challenges. ACS Energy Lett. 2017, 2, 2187-2204.

(14) Winsberg, J.; Hagemann, T.; Janoschka, T.; Hager, M. D.; Schubert, U. S. Redox-Flow Batteries: From Metals to Organic Redox-Active Materials. Angew. Chem., Int. Ed. 2017, 56, 686-711.

(15) Ding, Y.; Zhang, C.; Zhang, L.; Zhou, Y.; Yu, G. Molecular engineering of organic electroactive materials for redox flow batteries. Chem. Soc. Rev. 2018, 47, 69-103.

(16) Beh, E. S.; De Porcellinis, D.; Gracia, R. L.; Xia, K. T.; Gordon, R. G.; Aziz, M. J. A Neutral pH Aqueous Organic-Organometallic Redox Flow Battery with Extremely High Capacity Retention. ACS Energy Lett. 2017, 2, 639-644.

(17) Luo, J.; Hu, B.; Debruler, C.; Bi, Y.; Zhao, Y.; Yuan, B.; Hu, M.; $\mathrm{Wu}, \mathrm{W}$.; Liu, T. L. Unprecedented Capacity and Stability of Ammonium Ferrocyanide Catholyte in $\mathrm{pH}$ Neutral Aqueous Redox Flow Batteries. Joule 2019, 3, 149-163.

(18) Milshtein, J. D.; Kaur, A. P.; Casselman, M. D.; Kowalski, J. A.; Modekrutti, S.; Zhang, P.; Harsha Attanayake, N.; Elliott, C. F.; Parkin, S. R.; Risko, C.; Brushett, F. R.; Odom, S. A. High-CurrentDensity, Long-Duration Cycling of Soluble Organic Active Species for Non-Aqueous Redox Flow Batteries. Energy Environ. Sci. 2016, 9, 3531-3543.

(19) Barton, A. F. M. Solubility parameters. Chem. Rev. 1975, 75 (6), $731-753$.

(20) Wei, X.; Cosimbescu, L.; Xu, W.; Hu, J. Z.; Vijayakumar, M.; Feng, J.; Hu, M. Y.; Deng, X.; Xiao, J.; Liu, J.; Sprenkle, V.; Wang, W. Towards High-Performance Nonaqueous Redox Flow Electrolyte Via Ionic Modification of Active Species. Adv. Energy Mater. 2015, 5 (1), 1400678.

(21) Attanayake, N. H.; Kowalski, J. A.; Greco, K. V.; Casselman, M. D.; Milshtein, J. D.; Chapman, S. J.; Parkin, S. R.; Brushett, F. R.; Odom, S. A. Tailoring Two-Electron-Donating Phenothiazines To Enable High-Concentration Redox Electrolytes for Use in Nonaqueous Redox Flow Batteries. Chem. Mater. 2019, 31 (12), 43534363.

(22) Huang, J.; Cheng, L.; Assary, R. S.; Wang, P.; Xue, Z.; Burrell, A. K.; Curtiss, L. A.; Zhang, L. Liquid Catholyte Molecules for Nonaqueous Redox Flow Batteries. Adv. Energy Mater. 2015, 5 (6), 1401782.

(23) Hu, B.; DeBruler, C.; Rhodes, Z.; Liu, T. L. Long-Cycling Aqueous Organic Redox Flow Battery (AORFB) toward Sustainable and Safe Energy Storage. J. Am. Chem. Soc. 2017, 139 (3), 12071214.

(24) Hu, B.; Liu, T. L. Two Electron Utilization of Methyl Viologen Anolyte in Nonaqueous Organic Redox Flow Battery. J. Energy Chem. 2018, 27, 1326-1332.

(25) Sevov, C. S.; Brooner, R. E. M.; Chénard, E.; Assary, R. S.; Moore, J. S.; Rodríguez-López, J.; Sanford, M. S. Evolutionary Design of Low Molecular Weight Organic Anolyte Materials for Applications in Nonaqueous Redox Flow Batteries. J. Am. Chem. Soc. 2015, 137 (45), 14465-14472.
(26) DeBruler, C.; Hu, B.; Moss, J.; Liu, X.; Luo, J.; Sun, Y.; Liu, T. L. Designer Two-Electron Storage Viologen Anolyte Materials for Neutral Aqueous Organic Redox Flow Batteries. Chem. 2017, 3, 961978

(27) Gerhardt, M. R.; Tong, L.; Gómez-Bombarelli, R.; Chen, Q.; Marshak, M. P.; Galvin, C. J.; Aspuru-Guzik, A.; Gordon, R. G.; Aziz, M. J. Anthraquinone Derivatives in Aqueous Flow Batteries. Adv. Energy Mater. 2017, 7 (8), 1601488.

(28) Huskinson, B.; Marshak, M. P.; Suh, C.; Er, S.; Gerhardt, M. R.; Galvin, C. J.; Chen, X.; Aspuru-Guzik, A.; Gordon, R. G.; Aziz, M. J. A Metal-Free Organic-Inorganic Aqueous Flow Battery. Nature 2014, 505 (7482), 195-198.

(29) Hendriks, K. H.; Sevov, C. S.; Cook, M. E.; Sanford, M. S. Multielectron Cycling of a Low-Potential Anolyte in Alkali Metal Electrolytes for Nonaqueous Redox Flow Batteries. ACS Energy Lett. 2017, 2, 2430-2435.

(30) Wedege, K.; Dražević, E.; Konya, D.; Bentien, A. Organic Redox Species in Aqueous Flow Batteries: Redox Potentials, Chemical Stability and Solubility. Sci. Rep. 2016, 6, 39101.

(31) Kowalski, J. A.; Casselman, M. D.; Kaur, A. P.; Milshtein, J. D.; Elliott, C. F.; Modekrutti, S.; Attanayake, N. H.; Zhang, N.; Parkin, S. R.; Risko, C.; Brushett, F. R.; Odom, S. A. A stable two-electrondonating phenothiazine for application in nonaqueous redox flow batteries. J. Mater. Chem. A 2017, 5 (46), 24371-24379.

(32) Luo, J.; Hu, B.; Debruler, C.; Liu, T. L. A $\pi$-Conjugation Extended Viologen as a Two-Electron Storage Anolyte for Total Organic Aqueous Redox Flow Batteries. Angew. Chem., Int. Ed. 2018, 57, 231-235.

(33) Ward, M. D.; White, J. R.; Bard, A. J. E Electrochemical investigation of the energetics of particulate titanium dioxide photocatalysts. The methyl viologen-acetate system. J. Am. Chem. Soc. 1983, 105 (1), 27-31.

(34) Nicholson, R. S. Theory and Application of Cyclic Voltammetry for Measurement of Electrode Reaction Kinetics. Anal. Chem. 1965, 37 (11), 1351-1355.

(35) Liu, T.; Wei, X.; Nie, Z.; Sprenkle, V.; Wang, W. A Total Organic Aqueous Redox Flow Battery Employing a Low Cost and Sustainable Methyl Viologen Anolyte and 4-HO-TEMPO Catholyte. Adv. Energy Mater. 2016, 6 (3), 1501449.

(36) Doris, S. E.; Ward, A. L.; Baskin, A.; Frischmann, P. D.; Gavvalapalli, N.; Chénard, E.; Sevov, C. S.; Prendergast, D.; Moore, J. S.; Helms, B. A. Macromolecular Design Strategies for Preventing Active-Material Crossover in Non-Aqueous All-Organic Redox-Flow Batteries. Angew. Chem., Int. Ed. 2017, 56 (6), 1595-1599.

(37) Hendriks, K. H.; Robinson, S. G.; Braten, M. N.; Sevov, C. S.; Helms, B. A.; Sigman, M. S.; Minteer, S. D.; Sanford, M. S. HighPerformance Oligomeric Catholytes for Effective Macromolecular Separation in Nonaqueous Redox Flow Batteries. ACS Cent. Sci. 2018, 4 (2), 189-196.

(38) Janoschka, T.; Martin, N.; Hager, M. D.; Schubert, U. S. An Aqueous Redox-Flow Battery with High Capacity and Power: The TEMPTMA/MV System. Angew. Chem., Int. Ed. 2016, 55 (46), 14427-14430.

(39) Janoschka, T.; Martin, N.; Martin, U.; Friebe, C.; Morgenstern, S.; Hiller, H.; Hager, M. D.; Schubert, U. S. An Aqueous, Polymerbased Redox-Flow Battery Using Non-corrosive, Safe, and Low-cost Materials. Nature 2015, 527 (7576), 78-81.

(40) DeBruler, C.; Hu, B.; Moss, J.; Luo, J.; Liu, T. L. A SulfonateFunctionalized Viologen Enabling Neutral Cation Exchange, Aqueous Organic Redox Flow Batteries toward Renewable Energy Storage. ACS Energy Lett. 2018, 3, 663-668.

(41) Darling, R. M.; Gallagher, K. G.; Kowalski, J. A.; Ha, S.; Brushett, F. R. Pathways to low-cost Electrochemical Energy Storage: A Comparison of Aqueous and Nonaqueous Flow Batteries. Energy Environ. Sci. 2014, 7 (11), 3459-3477.

(42) Dieterich, V.; Milshtein, J. D.; Barton, J. L.; Carney, T. J.; Darling, R. M.; Brushett, F. R. Estimating the cost of organic battery active materials: a case study on anthraquinone disulfonic acid. Transl. Mater. Res. 2018, 5 (3), 034001. 
(43) Marcilla, R.; Navalpotro, p.; Anderson, m.; Palma, j. An Innovative Concept of Membrane-Free Redox Flow Battery by Using Two Immiscible Redox Electrolytes. Angew. Chem., Int. Ed. 2017, 56, 12460-12465.

(44) Yang, B.; Hoober-Burkhardt, L.; Wang, F.; Surya Prakash, G. K.; Narayanan, S. R. An Inexpensive Aqueous Flow Battery for LargeScale Electrical Energy Storage Based on Water-Soluble Organic Redox Couples. J. Electrochem. Soc. 2014, 161 (9), A1371-A1380.

(45) Lin, K.; Chen, Q.; Gerhardt, M. R.; Tong, L.; Kim, S. B.; Eisenach, L.; Valle, A. W.; Hardee, D.; Gordon, R. G.; Aziz, M. J.; Marshak, M. P. Alkaline Quinone Flow Battery. Science 2015, 349 (6255), 1529-1532.

(46) Lin, K.; Gómez-Bombarelli, R.; Beh, E. S.; Tong, L.; Chen, Q.; Valle, A.; Aspuru-Guzik, A.; Aziz, M. J.; Gordon, R. G. A Redox-Flow Battery with An Alloxazine-based Organic Electrolyte. Nat. Energy 2016, 1, 16102 .

(47) Kwabi, D. G.; Lin, K.; Ji, Y.; Kerr, E. F.; Goulet, M.-A.; De Porcellinis, D.; Tabor, D. P.; Pollack, D. A.; Aspuru-Guzik, A.; Gordon, R. G.; Aziz, M. J. Alkaline Quinone Flow Battery with Long Lifetime at $\mathrm{pH}$ 12. Joule 2018, 2 (9), 1894-1906.

(48) Yang, Z.; Tong, L.; Tabor, D. P.; Beh, E. S.; Goulet, M.-A.; De Porcellinis, D.; Aspuru-Guzik, A.; Gordon, R. G.; Aziz, M. J. Alkaline Benzoquinone Aqueous Flow Battery for Large-Scale Storage of Electrical Energy. Adv. Energy Mater. 2018, 8, 1702056.

(49) Ji, Y.; Goulet, M.-A.; Pollack, D. A.; Kwabi, D. G.; Jin, S.; De Porcellinis, D.; Kerr, E. F.; Gordon, R. G.; Aziz, M. J. A PhosphonateFunctionalized Quinone Redox Flow Battery at Near-Neutral pH with Record Capacity Retention Rate. Adv. Energy Mater. 2019, 9 (12), 1900039.

(50) Hu, B.; Tang, Y.; Luo, J.; Grove, G.; Guo, Y.; Liu, T. L. Improved Radical Stability of Viologen Anolytes in Aqueous Organic Redox Flow Batteries. Chem. Commun. 2018, 54, 6871-6874.

(51) Luo, J.; Wu, W.; Debruler, C.; Hu, B.; Hu, M.; Liu, T. L. A 1.51 $\mathrm{V} \mathrm{pH}$ neutral redox flow battery towards scalable energy storage. J. Mater. Chem. A 2019, 7 (15), 9130-9136.

(52) Liu, Y.; Goulet, M.-A.; Tong, L.; Liu, Y.; Ji, Y.; Wu, L.; Gordon, R. G.; Aziz, M. J.; Yang, Z.; Xu, T. A Long-Lifetime All-Organic Aqueous Flow Battery Utilizing TMAP-TEMPO Radical. Chem. 2019, 5 (7), 1861-1870.

(53) Nutting, J. E.; Rafiee, M.; Stahl, S. S. Tetramethylpiperidine NOxyl (TEMPO), Phthalimide N-Oxyl (PINO), and Related N-Oxyl Species: Electrochemical Properties and Their Use in Electrocatalytic Reactions. Chem. Rev. 2018, 118 (9), 4834-4885.

(54) Janiszewska, A. M.; Grzeszczuk, M. Mechanistic - Kinetic Scheme of Oxidation/Reduction of TEMPO Involving Hydrogen Bonded Dimer. RDE Probe for Availability of Protons in Reaction Environment. Electroanalysis 2004, 16 (20), 1673-1681.

(55) Fish, J. R.; Swarts, S. G.; Sevilla, M. D.; Malinski, T. Electrochemistry and spectroelectrochemistry of nitroxyl free radicals. J. Phys. Chem. 1988, 92 (13), 3745-3751.

(56) Nilsen, A.; Braslau, R. Nitroxide decomposition: Implications toward nitroxide design for applications in living free-radical polymerization. J. Polym. Sci., Part A: Polym. Chem. 2006, 44 (2), 697-717.

(57) Zotti, G.; Schiavon, G.; Zecchin, S.; Favretto, D. Dioxygendecomposition of ferrocenium molecules in acetonitrile: The nature of the electrode-fouling films during ferrocene electrochemistry. $J$. Electroanal. Chem. 1998, 456 (1), 217-221.

(58) Prins, R.; Korswagen, A. R.; Kortbeek, A. G. T. G. Decomposition of the ferricenium cation by nucleophilic reagents. $J$. Organomet. Chem. 1972, 39 (2), 335-344.

(59) Geraskina, M. R.; Dutton, A. S.; Juetten, M. J.; Wood, S. A.; Winter, A. H. The Viologen Cation Radical Pimer: A Case of Dispersion-Driven Bonding. Angew. Chem., Int. Ed. 2017, 56 (32), 9435-9439.

(60) Huang, J.; Yang, Z.; Murugesan, V.; Walter, E.; Hollas, A.; Pan, B.; Assary, R. S.; Shkrob, I. A.; Wei, X.; Zhang, Z. Spatially Constrained Organic Diquat Anolyte for Stable Aqueous Flow Batteries. ACS Energy Lett. 2018, 3 (10), 2533-2538.
(61) Farrington, J. A.; Ledwith, A.; Stam, M. F. Cation-radicals: oxidation of methoxide ion with 1,1'-dimethyl-4,4'-bipyridylium dichloride (paraquat dichloride). Chem. Commun. 1969, 0 (6), 259-260.

(62) Clark, C. D.; Debad, J. D.; Yonemoto, E. H.; Mallouk, T. E.; Bard, A. J. Effect of Oxygen on Linked Ru(bpy)32+-Viologen Species and Methylviologen: A Reinterpretation of the Electrogenerated Chemiluminescence. J. Am. Chem. Soc. 1997, 119 (43), 1052510531.

(63) Coury, L. Conductance Measurements Part 1: Theory Current Separations; 1999; Vol. 18, pp 91-96.

(64) Xu, Y.; Wen, Y.; Cheng, J.; Yanga, Y.; Xie, Z.; Cao, G., Novel organic redox flow batteries using soluble quinonoid compounds as positive materials. In World Non-Grid-Connected Wind Power and Energy Conference, 2009; WNWEC 2009 IEEE: Nanjing, China, 2009; pp 1-4.

(65) Xu, Y.; Wen, Y.-H.; Cheng, J.; Cao, G.-P.; Yang, Y.-S. A study of tiron in aqueous solutions for redox flow battery application. Electrochim. Acta 2010, 55 (3), 715-720.

(66) Huskinson, B.; Marshak, M. P.; Gerhardt, M. R.; Aziz, M. J. Cycling of a Quinone-Bromide Flow Battery for Large-Scale Electrochemical Energy Storage. ECS Trans. 2014, 61, 27.

(67) Li, G.; Jia, Y.; Zhang, S.; Li, X.; Li, J.; Li, L. The crossover behavior of bromine species in the metal-free flow battery. J. Appl. Electrochem. 2017, 47 (2), 261-272.

(68) Goulet, M.-A.; Aziz, M. J. Flow Battery Molecular Reactant Stability Determined by Symmetric Cell Cycling Methods. J. Electrochem. Soc. 2018, 165 (7), A1466-A1477.

(69) Carney, T. J.; Collins, S. J.; Moore, J. S.; Brushett, F. R. Concentration-Dependent Dimerization of Anthraquinone Disulfonic Acid and Its Impact on Charge Storage. Chem. Mater. 2017, 29 (11), 4801-4810.

(70) Yang, B.; Hoober-Burkhardt, L.; Krishnamoorthy, S.; Murali, A.; Prakash, G. K. S.; Narayanan, S. R. High-Performance Aqueous Organic Flow Battery with Quinone-Based Redox Couples at Both Electrodes. J. Electrochem. Soc. 2016, 163 (7), A1442-A1449.

(71) Hoober-Burkhardt, L.; Krishnamoorthy, S.; Yang, B.; Murali, A.; Nirmalchandar, A.; Prakash, G. K. S.; Narayanan, S. R. A New Michael-Reaction-Resistant Benzoquinone for Aqueous Organic Redox Flow Batteries. J. Electrochem. Soc. 2017, 164 (4), A600-A607.

(72) Park, M.; Beh, E. S.; Fell, E. M.; Jing, Y.; Kerr, E. F.; De Porcellinis, D.; Goulet, M.-A.; Ryu, J.; Wong, A. A.; Gordon, R. G.; Cho, J.; Aziz, M. J. A High Voltage Aqueous Zinc-Organic Hybrid Flow Battery. Adv. Energy Mater. 2019, 9, 1900694.

(73) Jin, S.; Jing, Y.; Kwabi, D. G.; Ji, Y.; Tong, L.; De Porcellinis, D.; Goulet, M.-A.; Pollack, D. A.; Gordon, R. G.; Aziz, M. J. A WaterMiscible Quinone Flow Battery with High Volumetric Capacity and Energy Density. ACS Energy Lett. 2019, 4 (6), 1342-1348.

(74) Hu, B.; Luo, J.; Hu, M.; Yuan, B.; Liu, T. L. A pH Neutral, Metal Free Aqueous Organic Redox Flow Battery Employing an Ammonium Anthraquinone Anolyte. Angew. Chem., Int. Ed. 2019, DOI: 10.1002/anie.201907934.

(75) Ji, Y.; Goulet, M.-A.; Pollack, D. A.; Kwabi, D. G.; Jin, S.; De Porcellinis, D.; Kerr, E. F.; Gordon, R. G.; Aziz, M. J. A PhosphonateFunctionalized Quinone Redox Flow Battery at Near-Neutral pH with Record Capacity Retention Rate. Adv. Energy Mater. 2019, 9, 1900039.

(76) Hollas, A.; Wei, X.; Murugesan, V.; Nie, Z.; Li, B.; Reed, D.; Liu, J.; Sprenkle, V.; Wang, W. A Biomimetic High-capacity Phenazine-based Anolyte for Aqueous Organic Redox Flow Batteries. Nat. Energy 2018, 3 (6), 508-514.

(77) Orita, A.; Verde, M. G.; Sakai, M.; Meng, Y. S. A biomimetic redox flow battery based on flavin mononucleotide. Nat. Commun. 2016, 7, 13230.

(78) Luo, J.; Sam, A.; Hu, B.; DeBruler, C.; Wei, X.; Wang, W.; Liu, T. L. Unraveling $\mathrm{pH}$ Dependent Cycling Stability of Ferricyanide/ Ferrocyanide in Redox Flow Batteries. Nano Energy 2017, 42, 215221. 
(79) Kolthoff, I. M.; Pearson, E. A. Stability of potassium ferrocyanide solutions. Ind. Eng. Chem., Anal. Ed. 1931, 3 (4), 381382.

(80) Wei, X.; Xu, W.; Huang, J.; Zhang, L.; Walter, E.; Lawrence, C.; Vijayakumar, M.; Henderson, W. A.; Liu, T.; Cosimbescu, L.; Li, B.; Sprenkle, V.; Wang, W. Radical Compatibility with Nonaqueous Electrolytes and Its Impact on an All-Organic Redox Flow Battery. Angew. Chem., Int. Ed. 2015, 54, 8684-8687.

(81) Cong, G.; Zhou, Y.; Li, Z.; Lu, Y.-C. A Highly Concentrated Catholyte Enabled by a Low-Melting-Point Ferrocene Derivative. ACS Energy Lett. 2017, 2 (4), 869-875.

(82) Zhao, Y.; Ding, Y.; Song, J.; Li, G.; Dong, G.; Goodenough, J. B.; Yu, G. Sustainable Electrical Energy Storage through the Ferrocene/Ferrocenium Redox Reaction in Aprotic Electrolyte. Angew. Chem., Int. Ed. 2014, 53 (41), 11036-11040.

(83) Ding, Y.; Zhao, Y.; Yu, G. A Membrane-Free Ferrocene-Based High-Rate Semiliquid Battery. Nano Lett. 2015, 15 (6), 4108-4113.

(84) Ding, Y.; Zhao, Y.; Li, Y.; Goodenough, J. B.; Yu, G. A HighPerformance All-metallocene-based, Non-aqueous Redox Flow Battery. Energy Environ. Sci. 2017, 10 (2), 491-497.

(85) Wang, W.; Xu, W.; Cosimbescu, L.; Choi, D.; Li, L.; Yang, Z. Anthraquinone with tailored structure for a nonaqueous metal-organic redox flow battery. Chem. Commun. 2012, 48 (53), 6669-6671.

(86) Potash, R. A.; McKone, J. R.; Conte, S.; Abruña, H. D. On the Benefits of a Symmetric Redox Flow Battery. J. Electrochem. Soc. 2016, 163 (3), A338-A344.

(87) Ding, Y.; Li, Y.; Yu, G. Exploring Bio-inspired Quinone-Based Organic Redox Flow Batteries: A Combined Experimental and Computational Study. Chem. 2016, 1 (5), 790-801.

(88) Huang, J.; Yang, Z.; Vijayakumar, M.; Duan, W.; Hollas, A.; Pan, B.; Wang, W.; Wei, X.; Zhang, L. A Two-Electron Storage Nonaqueous Organic Redox Flow Battery. Adv. Sustain. Syst. 2018, 2, 1700131.

(89) Brushett, F. R.; Vaughey, J. T.; Jansen, A. N. An All-Organic Non-aqueous Lithium-Ion Redox Flow Battery. Adv. Energy Mater. 2012, 2 (11), 1390-1396.

(90) Huang, J.; Su, L.; Kowalski, J. A.; Barton, J. L.; Ferrandon, M.; Burrell, A. K.; Brushett, F. R.; Zhang, L. A subtractive approach to molecular engineering of dimethoxybenzene-based redox materials for non-aqueous flow batteries. J. Mater. Chem. A 2015, 3 (29), 1497114976.

(91) Wei, X.; Duan, W.; Huang, J.; Zhang, L.; Li, B.; Reed, D.; Xu, W.; Sprenkle, V.; Wang, W. A High-Current, Stable Nonaqueous Organic Redox Flow Battery. ACS Energy Lett. 2016, 1 (4), 705-711.

(92) Duan, W.; Huang, J.; Kowalski, J. A.; Shkrob, I. A.; Vijayakumar, M.; Walter, E.; Pan, B.; Yang, Z.; Milshtein, J. D.; Li, B.; Liao, C.; Zhang, Z.; Wang, W.; Liu, J.; Moore, J. S.; Brushett, F. R.; Zhang, L.; Wei, X. Wine-Dark Sea" in an Organic Flow Battery: Storing Negative Charge in 2,1,3-Benzothiadiazole Radicals Leads to Improved Cyclability. ACS Energy Lett. 2017, 2 (5), 1156-1161.

(93) Zhang, J.; Yang, Z.; Shkrob, I. A.; Assary, R. S.; Tung, S. o.; Silcox, B.; Duan, W.; Zhang, J.; Su, C. C.; Hu, B.; Pan, B.; Liao, C.; Zhang, Z.; Wang, W.; Curtiss, L. A.; Thompson, L. T.; Wei, X.; Zhang, L. Annulated Dialkoxybenzenes as Catholyte Materials for Non-aqueous Redox Flow Batteries: Achieving High Chemical Stability through Bicyclic Substitution. Adv. Energy Mater. 2017, 7, 1701272.

(94) Wei, X.; Xu, W.; Vijayakumar, M.; Cosimbescu, L.; Liu, T.; Sprenkle, V.; Wang, W. TEMPO-Based Catholyte for High-Energy Density Nonaqueous Redox Flow Batteries. Adv. Mater. 2014, 26 (45), 7649-7653.

(95) Sukegawa, T.; Masuko, I.; Oyaizu, K.; Nishide, H. Expanding the Dimensionality of Polymers Populated with Organic Robust Radicals toward Flow Cell Application: Synthesis of TEMPOCrowded Bottlebrush Polymers Using Anionic Polymerization and ROMP. Macromolecules 2014, 47 (24), 8611-8617.

(96) Takechi, K.; Kato, Y.; Hase, Y. A Highly Concentrated Catholyte Based on a Solvate Ionic Liquid for Rechargeable Flow Batteries. Adv. Mater. 2015, 27 (15), 2501-2506.
(97) Winsberg, J.; Janoschka, T.; Morgenstern, S.; Hagemann, T.; Muench, S.; Hauffman, G.; Gohy, J.-F.; Hager, M. D.; Schubert, U. S. Poly(TEMPO)/Zinc Hybrid-Flow Battery: A Novel, "Green," High Voltage, and Safe Energy Storage System. Adv. Mater. 2016, 28 (11), $2238-2243$.

(98) Milshtein, J. D.; Barton, J. L.; Darling, R. M.; Brushett, F. R. 4acetamido-2,2,6,6-tetramethylpiperidine-1-oxyl as a model organic redox active compound for nonaqueous flow batteries. J. Power Sources 2016, 327, 151-159.

(99) Duan, W.; Vemuri, R. S.; Milshtein, J. D.; Laramie, S.; Dmello, R. D.; Huang, J.; Zhang, L.; Hu, D.; Vijayakumar, M.; Wang, W.; Liu, J.; Darling, R. M.; Thompson, L.; Smith, K.; Moore, J. S.; Brushett, F. R.; Wei, X. A symmetric organic-based nonaqueous redox flow battery and its state of charge diagnostics by FTIR. J. Mater. Chem. A 2016, 4, $5448-5456$.

(100) Hagemann, T.; Winsberg, J.; Haupler, B.; Janoschka, T.; Gruber, J. J.; Wild, A.; Schubert, U. S. A bipolar nitronyl nitroxide small molecule for an all-organic symmetric redox-flow battery. NPG Asia Mater. 2017, 9, No. e340.

(101) Montoto, E. C.; Nagarjuna, G.; Hui, J.; Burgess, M.; Sekerak, N. M.; Hernández-Burgos, K.; Wei, T.-S.; Kneer, M.; Grolman, J.; Cheng, K. J.; Lewis, J. A.; Moore, J. S.; Rodríguez-López, J. Redox Active Colloids as Discrete Energy Storage Carriers. J. Am. Chem. Soc. 2016, 138 (40), 13230-13237.

(102) Montoto, E. C.; Nagarjuna, G.; Moore, J. S.; Rodríguez-López, J. Redox Active Polymers for Non-Aqueous Redox Flow Batteries: Validation of the Size-Exclusion Approach. J. Electrochem. Soc. 2017, 164 (7), A1688-A1694.

(103) Sevov, C. S.; Hickey, D. P.; Cook, M. E.; Robinson, S. G.; Barnett, S.; Minteer, S. D.; Sigman, M. S.; Sanford, M. S. Physical Organic Approach to Persistent, Cyclable, Low-Potential Electrolytes for Flow Battery Applications. J. Am. Chem. Soc. 2017, 139 (8), 29242927.

(104) Sevov, C. S.; Samaroo, S. K.; Sanford, M. S. Cyclopropenium Salts as Cyclable, High-Potential Catholytes in Nonaqueous Media. Adv. Energy Mater. 2017, 7 (5), 1602027.

(105) Winsberg, J.; Hagemann, T.; Muench, S.; Friebe, C.; Häupler, B.; Janoschka, T.; Morgenstern, S.; Hager, M. D.; Schubert, U. S. Poly(boron-dipyrromethene)-A Redox-Active Polymer Class for Polymer Redox-Flow Batteries. Chem. Mater. 2016, 28 (10), 34013405.

(106) Xing, X.; Huo, Y.; Wang, X.; Zhao, Y.; Li, Y. A benzophenonebased anolyte for high energy density all-organic redox flow battery. Int. J. Hydrogen Energy 2017, 42, 17488-17494.

(107) Milton, M.; Cheng, Q.; Yang, Y.; Nuckolls, C.; Hernández Sánchez, R.; Sisto, T. J. Molecular Materials for Nonaqueous Flow Batteries with a High Coulombic Efficiency and Stable Cycling. Nano Lett. 2017, 17 (12), 7859-7863.

(108) $\mathrm{Xu}, \mathrm{K}$. Electrolytes and Interphases in Li-Ion Batteries and Beyond. Chem. Rev. 2014, 114 (23), 11503-11618.

(109) Matsuda, Y.; Tanaka, K.; Okada, M.; Takasu, Y.; Morita, M.; Matsumura-Inoue, T. A rechargeable redox battery utilizing ruthenium complexes with non-aqueous organic electrolyte. J. Appl. Electrochem. 1988, 18 (6), 909-914.

(110) Chakrabarti, M. H.; Lindfield Roberts, E. P.; Saleem, M. Charge-Discharge Performance of a Novel Undivided Redox Flow Battery for Renewable Energy Storage. Int. J. Green Energy 2010, 7 (4), 445-460.

(111) Cabrera, P. J.; Yang, X.; Suttil, J. A.; Hawthorne, K. L.; Brooner, R. E. M.; Sanford, M. S.; Thompson, L. T. Complexes Containing Redox Noninnocent Ligands for Symmetric, Multielectron Transfer Nonaqueous Redox Flow Batteries. J. Phys. Chem. C 2015, 119 (28), 15882-15889.

(112) Cabrera, P. J.; Yang, X.; Suttil, J. A.; Hawthorne, K. L.; Brooner, R. E. M.; Sanford, M. S.; Thompson, L. T. Complexes Containing Redox Noninnocent Ligands for Symmetric, Multielectron Transfer Nonaqueous Redox Flow Batteries. J. Phys. Chem. C 2015, 119 (28), 15882-15889. 
(113) Suttil, J. A.; Kucharyson, J. F.; Escalante-Garcia, I. L.; Cabrera, P. J.; James, B. R.; Savinell, R. F.; Sanford, M. S.; Thompson, L. T. Metal acetylacetonate complexes for high energy density non-aqueous redox flow batteries. J. Mater. Chem. A 2015, 3 (15), 7929-7938.

(114) Sevov, C. S.; Fisher, S. L.; Thompson, L. T.; Sanford, M. S. Mechanism-Based Development of a Low-Potential, Soluble, and Cyclable Multielectron Anolyte for Nonaqueous Redox Flow Batteries. J. Am. Chem. Soc. 2016, 138 (47), 15378-15384.

(115) Yang, C.; Nikiforidis, G.; Park, J. Y.; Choi, J.; Luo, Y.; Zhang, L.; Wang, S.-C.; Chan, Y.-T.; Lim, J.; Hou, Z.; Baik, M.-H.; Lee, Y.; Byon, H. R. Designing Redox-Stable Cobalt-Polypyridyl Complexes for Redox Flow Batteries: Spin-Crossover Delocalizes Excess Charge. Adv. Energy Mater. 2018, 8, 1702897.

(116) Li, Z.; Li, S.; Liu, S.; Huang, K.; Fang, D.; Wang, F.; Peng, S. Electrochemical Properties of an All-Organic Redox Flow Battery Using 2,2,6,6-Tetramethyl-1-Piperidinyloxy and N-Methylphthalimide. Electrochem. Solid-State Lett. 2011, 14 (12), A171-A173.

(117) Winsberg, J.; Stolze, C.; Muench, S.; Liedl, F.; Hager, M. D.; Schubert, U. S. TEMPO/Phenazine Combi-Molecule: A RedoxActive Material for Symmetric Aqueous Redox-Flow Batteries. ACS Energy Lett. 2016, 1 (5), 976-980.

(118) Charlton, G. D.; Barbon, S. M.; Gilroy, J. B.; Dyker, C. A. A bipolar verdazyl radical for a symmetric all-organic redox flow-type battery. J. Energy Chem. 2019, 34, 52-56.

(119) Burgess, M.; Chénard, E.; Hernández-Burgos, K.; Nagarjuna, G.; Assary, R. S.; Hui, J.; Moore, J. S.; Rodríguez-López, J. Impact of Backbone Tether Length and Structure on the Electrochemical Performance of Viologen Redox Active Polymers. Chem. Mater. 2016, 28 (20), 7362-7374.

(120) Xu, W.; Wang, J.; Ding, F.; Chen, X.; Nasybulin, E.; Zhang, Y.; Zhang, J.-G. Lithium metal anodes for rechargeable batteries. Energy Environ. Sci. 2014, 7 (2), 513-537.

(121) Jia, C.; Pan, F.; Zhu, Y. G.; Huang, Q.; Lu, L.; Wang, Q. Highenergy density nonaqueous all redox flow lithium battery enabled with a polymeric membrane. Science Advances 2015, 1 (10), No. e1500886. (122) Zhou, M.; Huang, Q.; Pham Truong, T. N.; Ghilane, J.; Zhu, Y. G.; Jia, C.; Yan, R.; Fan, L.; Randriamahazaka, H.; Wang, Q. Nernstian-Potential-Driven Redox-Targeting Reactions of Battery Materials. Chem. 2017, 3, 1036-1049.

(123) Yan, R.; Wang, Q. Redox-Targeting-Based Flow Batteries for Large-Scale Energy Storage. Adv. Mater. 2018, 30 (47), 1802406.

(124) Pan, F.; Yang, J.; Huang, Q.; Wang, X.; Huang, H.; Wang, Q. Redox Targeting of Anatase $\mathrm{TiO} 2$ for Redox Flow Lithium-Ion Batteries. Adv. Energy Mater. 2014, 4 (15), 1400567.

(125) Huang, Q.; Yang, J.; Ng, C. B.; Jia, C.; Wang, Q. A redox flow lithium battery based on the redox targeting reactions between LiFePO4 and iodide. Energy Environ. Sci. 2016, 9 (3), 917-921.

(126) Zhu, Y. G.; Goh, F. W. T.; Yan, R.; Wu, S.; Adams, S.; Wang, Q. Synergistic oxygen reduction of dual redox catalysts boosting the power of lithium-air battery. Phys. Chem. Chem. Phys. 2018, 20 (44), 27930-27936.

(127) Yu, J.; Fan, L.; Yan, R.; Zhou, M.; Wang, Q. Redox TargetingBased Aqueous Redox Flow Lithium Battery. ACS Energy Lett. 2018, 3 (10), 2314-2320.

(128) Yu, M.; McCulloch, W. D.; Huang, Z.; Trang, B. B.; Lu, J.; Amine, K.; Wu, Y. Solar-powered electrochemical energy storage: an alternative to solar fuels. J. Mater. Chem. A 2016, 4 (8), 2766-2782. (129) Li, W.; Fu, H.-C.; Zhao, Y.; He, J.-H.; Jin, S. 14.1\% Efficient Monolithically Integrated Solar Flow Battery. Chem. 2018, 4, 26442657.

(130) Liao, S.; Zong, X.; Seger, B.; Pedersen, T.; Yao, T.; Ding, C.; Shi, J.; Chen, J.; Li, C. Integrating a dual-silicon photoelectrochemical cell into a redox flow battery for unassisted photocharging. Nat. Commun. 2016, 7, 11474.

(131) Yu, M.; McCulloch, W. D.; Beauchamp, D. R.; Huang, Z.; Ren, X.; Wu, Y. Aqueous Lithium-Iodine Solar Flow Battery for the Simultaneous Conversion and Storage of Solar Energy. J. Am. Chem. Soc. 2015, 137 (26), 8332-8335.
(132) Wedege, K.; Azevedo, J.; Khataee, A.; Bentien, A.; Mendes, A. Direct Solar Charging of an Organic-Inorganic, Stable, and Aqueous Alkaline Redox Flow Battery with a Hematite Photoanode. Angew. Chem. 2016, 128 (25), 7258-7263.

(133) Cao, L.; Skyllas-Kazacos, M.; Wang, D.-W. Solar Redox Flow Batteries: Mechanism, Design, and Measurement. Adv. Sustainable Syst. 2018, 2 (8-9), 1800031.

(134) Wedege, K.; Bae, D.; Smith, W. A.; Mendes, A.; Bentien, A. Solar Redox Flow Batteries with Organic Redox Couples in Aqueous Electrolytes: A Minireview. J. Phys. Chem. C 2018, 122, 25729. 